\title{
Molecular Recognition and Shape Studies of 3- and 4-Substituted Diarylamide Quasiracemates
}

\author{
Ali K. Brandt ${ }^{1}$, Derek J. Boyle ${ }^{1}$, Jacob P. Butler ${ }^{1}$, Abigail R. Gillingham ${ }^{1}$, Scott E. Penner ${ }^{1}$, \\ Jacqueline M. Spaniol $^{2}$, Alaina K. Stockdill ${ }^{3}$, Morgan M. Vanderwall ${ }^{1}$, Almat Yeraly ${ }^{3}$, Diana R. Schepens ${ }^{3, *(D)}$ \\ and Kraig A. Wheeler ${ }^{1, *(\mathbb{D})}$ \\ 1 Department of Chemistry, Whitworth University, Spokane, WA 99251, USA; \\ abrandt20@my.whitworth.edu (A.K.B.); dboyle19@my.whitworth.edu (D.J.B.); \\ jbutler20@my.whitworth.edu (J.P.B.); agillingham20@my.whitworth.edu (A.R.G.); \\ spenner21@my.whitworth.edu (S.E.P.); mvanderwall19@my.whitworth.edu (M.M.V.) \\ 2 Department of Chemistry, Eastern Illinois University, Charleston, IL 61920, USA; jmspaniol3@gmail.com \\ 3 Department of Mathematics and Computer Science, Whitworth University, Spokane, WA 99251, USA; \\ astockdill22@my.whitworth.edu (A.K.S.); ayeraly20@my.whitworth.edu (A.Y.) \\ * Correspondence: dschepens@whitworth.edu (D.R.S.); kraigwheeler@whitworth.edu (K.A.W.)
}

\section{check for}

updates

Citation: Brandt, A.K.; Boyle, D.J.; Butler, J.P.; Gillingham, A.R.; Penner, S.E.; Spaniol, J.M.; Stockdill, A.K.; Vanderwall, M.M.; Yeraly, A.; Schepens, D.R.; et al. Molecular Recognition and Shape Studies of 3 and 4-Substituted Diarylamide Quasiracemates. Crystals 2021, 11 1596. https://doi.org/10.3390/ cryst11121596

Academic Editor: Klaus Merz

Received: 30 November 2021 Accepted: 16 December 2021 Published: 20 December 2021

Publisher's Note: MDPI stays neutral with regard to jurisdictional claims in published maps and institutional affiliations.

Copyright: (C) 2021 by the authors Licensee MDPI, Basel, Switzerland. This article is an open access article distributed under the terms and conditions of the Creative Commons Attribution (CC BY) license (https:// creativecommons.org/licenses/by/ $4.0 /)$

\begin{abstract}
Families of quasiracemic materials constructed from 3- and 4-substituted chiral diarylamide molecular frameworks were prepared, where the imposed functional group differences systematically varied from $\mathrm{H}$ to $\mathrm{CF}_{3}-9$ unique components for each isomeric framework. Cocrystallization from the melt via hot stage thermomicroscopy using all possible racemic and quasiracemic combinations probed the structural boundaries of quasiracemate formation. The crystal structures and lattice energies (differential scanning calorimetry and lattice energy calculations) for many of these systems showed that quasienantiomeric components organize with near inversion symmetry and lattice energetics closely resembling those found in the racemic counterparts. This study also compared the shape space of pairs of quasienantiomers using an in silico alignment-based method to approximate the differences in molecular shape and provide a diagnostic tool for quasiracemate prediction. Comparing these results to our recent report on related 2-substituted diarylamide quasiracemates shows that functional group position can have a marked effect on quasiracemic behavior and provide critical insight to a more complete shape space, essential for defining molecular recognition processes.
\end{abstract}

Keywords: quasiracemic materials; crystal engineering; molecular recognition; molecular shape; molecular volume comparison

\section{Introduction}

Crystalline materials constructed from pairs of near enantiomers, commonly referred to as quasiracemates or quasiracemic compounds [1,2], hold significance to the materials sciences because they provide vital opportunities to examine the effects of molecular topology on supramolecular assembly. The majority of studies in this field seeking to understand how structural features influence molecular recognition events often examine cohesive noncovalent interactions via molecular crystals. Given that molecule-molecule contacts can be robust and directional (e.g., hydrogen and halogen bonds), their influence on crystal alignment has been assessed [3-9], conditional exceptions determined [10,11], and in many cases, their contribution to crystal stabilization reliably quantified [12-16]. The supramolecular process of pairing quasienantiomers $\left(R-X\right.$ and $\left.S-X^{\prime}\right)$ in molecular crystals can be quite different, where the complementary shapes of the starting components provide the principal driving force for constructing molecular assemblies. Crystal packing motifs involving quasiracemates nearly always mimic the centrosymmetric alignment observed with their racemic counterparts because the thermodynamic stability of these motifs often exceeds those found in the crystal assemblies constructed exclusively from 
either the $R-X$ or $S-X^{\prime}$ building blocks $[17,18]$. The only known exceptions to this structural proclivity for inversion symmetry are recent reports on tartaramide/malamide [19] and amino acid [20], quasiracemates, where the quasienantiomeric components either mimic approximate two-fold symmetry or deviate drastically from the expected near inversion symmetry alignment.

While the quasiracemic approach to material design has proven useful for various applications such as crystallization [21-27], asymmetric synthesis [28], and chemical detection/separation [28-31], only recently has the structural boundaries of quasiracemate formation been examined in detail [32]. Boundary identification was achieved by studying a homologous family of structurally simple chiral 2-substituted diarylamides where the pendant functional group incrementally varied from $-\mathrm{H}$ to $--\mathrm{C}_{6} \mathrm{H}_{5}$ ). Processing all quasienantiomeric combinations via hot stage polarized light microscopy effectively mapped the shape space of quasiracemate formation for this chemical system. As anticipated, the outcomes from this study emphasized that pairing topologically similar quasienantiomers (e.g., $\mathrm{H} / \mathrm{F}$ and $\mathrm{Cl} / \mathrm{Br}$ ) tolerated cocrystallization and attempts to assemble widely different $R-\mathrm{X}$ and $\mathrm{S}-\mathrm{X}^{\prime}$ components (e.g., $\mathrm{H} / \mathrm{NO}_{2}$ and $\mathrm{F} / \mathrm{CF}_{3}$ ) resulted in conglomerate formation. This study's results drew attention to successful quasiracemate formation from previously unreported or unanticipated functional group pairs such as the $\mathrm{Cl} / \mathrm{CF}_{3}$ and $\mathrm{CN} / \mathrm{I}$. Here, we build on this work by investigating the shape space of quasiracemate formation using 3- and 4-substituted diarylamides (Scheme 1). Though these chemical systems are closely related to the previous 2-substituted diarylamides, it is well known that subtle structural modifications often translate to significant differences in crystal packing preferences $[33,34]$. As such, we expect that the information provided from this study will draw attention to the consequence of molecular shape to supramolecular assembly and how isomeric quasiracemates provide critical insight to a more complete shape space essential for defining molecular recognition processes.

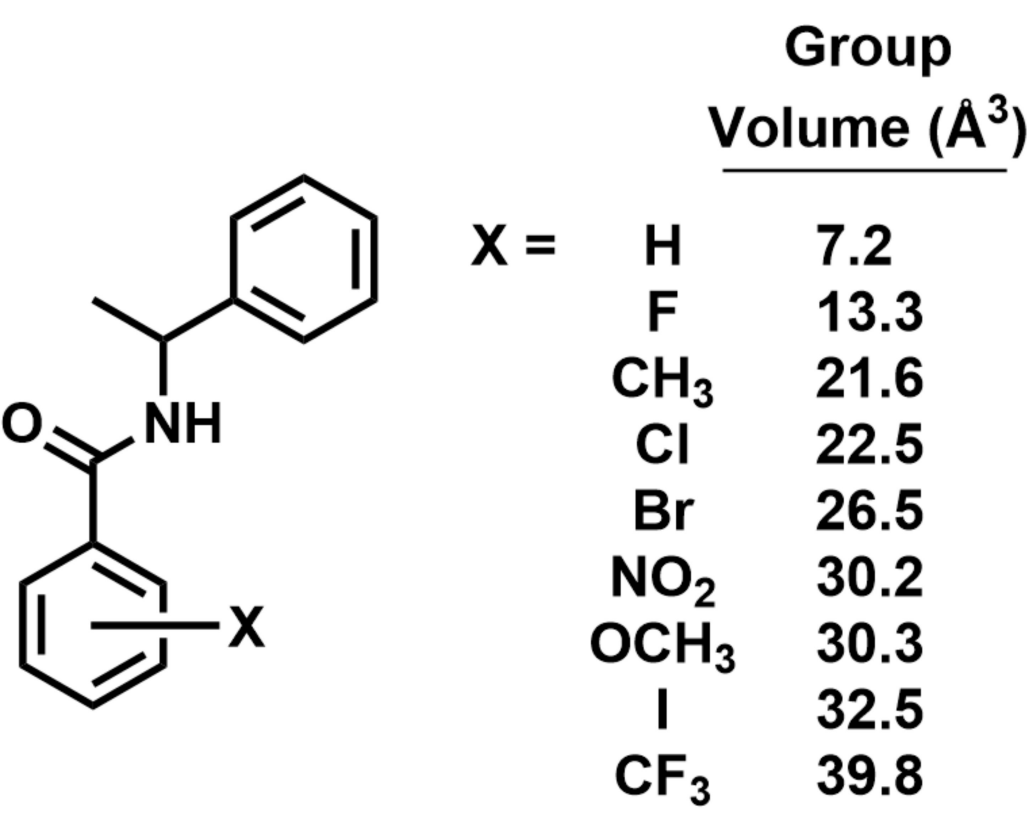

Scheme 1. The chemical framework of 3- and 4-substituted diarylamides with functional group volumes (volume data taken from ref. [18]).

\section{Materials and Methods}

\subsection{Synthetic and Crystal Growth Procedures}

A family of chiral 3- and 4-substituted diarylamide derivatives were prepared using the following general procedure starting from either the acid chloride or carboxylic acid. This procedure is based on previously described literature reports [18,32] of closely related secondary amide compounds. 
(R)-N-(3-Fluorobenzoyl)methylbenzylamine-(R)-3-F. To a 100-mL round-bottom flask containing a stir bar and $1.0 \mathrm{~mL}$ of thionyl chloride $(13.8 \mathrm{mmol})$ at $0{ }^{\circ} \mathrm{C}$ was added 3fluorobenzoic acid $(0.500 \mathrm{~g}, 3.57 \mathrm{mmol})$. After dissolution, the reaction mixture was allowed to warm to room temperature and then refluxed for $2.5 \mathrm{~h}$ to give a homogeneous yellow solution. Excess thionyl chloride was removed by washing the mixture with $15 \mathrm{~mL}$ of hexanes and the mixture was reduced using a mechanical diffusion pump to give a yellow oil. Without further purification, the acid chloride was treated with a mixture of $(R)-(+)$ - $\alpha$-methylbenzylamine $(0.518 \mathrm{~g}, 4.28 \mathrm{mmol})$ dissolved in $5 \mathrm{~mL}$ of dichloromethane and stirred overnight at room temperature. The reaction mixture was then extracted in succession with $10 \mathrm{~mL} \mathrm{H} \mathrm{H}_{2} \mathrm{O}, 10 \mathrm{~mL}$ saturated $\mathrm{NaHCO}_{3}, 10 \mathrm{~mL} 4 \mathrm{M} \mathrm{HCl}$, and $10 \mathrm{~mL} \mathrm{H}_{2} \mathrm{O}$. The organic layer was dried using anhydrous magnesium sulfate, reduced under vacuo, and washed with $10 \mathrm{~mL}$ of hexanes to give a solid colorless product $(0.623 \mathrm{~g}, 71.7 \%$ yield).

X-ray quality crystals were obtained after 1-2 days via slow evaporation at room temperature using a 1:1 ratio of hexanes: dichloromethane.

${ }^{1} \mathrm{H}$ NMR (400 MHz, $\left.\mathrm{CDCl}_{3}\right): \delta 7.52-7.45\left(\mathrm{~m}, 2 \mathrm{H}, \mathrm{C}_{\mathrm{Ar}}-\mathrm{H}\right) ; 7.42-7.25\left(\mathrm{~m}, 6 \mathrm{H}, \mathrm{C}_{\mathrm{Ar}}-\mathrm{H}\right)$; 7.21-7.14 (m, 1H, $\left.\mathrm{C}_{\mathrm{Ar}}-\mathrm{H}\right) ; 6.28(\mathrm{br} \mathrm{d}, J=6.5 \mathrm{~Hz}, 1 \mathrm{H}, \mathrm{N}-\mathrm{H}) ; 5.31\left(\mathrm{dq}, J=6.5\right.$ and $6.9 \mathrm{~Hz},{ }^{1} \mathrm{H}$, $\left.\mathrm{C}_{\mathrm{sp} 3}-\mathrm{H}\right) ; 1.60\left(\mathrm{~d}, \mathrm{~J}=6.9 \mathrm{~Hz}, 3 \mathrm{H}, \mathrm{CH}_{3}\right)$.

Section S1 of the Supplementary Materials contains ${ }^{1} \mathrm{H}$ NMR and percent yield data for the additional compounds included in this study.

\subsection{Hot Stage Polarized Thermomicroscopy}

The hot stage microscopy experiments were performed using an Instec HCS 302 hot stage connected to an Instec $m K 2000$ temperature controller equipped with the WINDV software package (V1.0.120820) (Instec, Boulder, CO, USA). Hot stage micrographs were collected via an optical polarizing microscope (Olympus SZX10) under a range of magnifications $(3.0-6.3 \times)$ using an attached video camera. Samples were prepared using standard glass microscope slides and coverslips. The higher melting point component was delivered first by heating the sample to the melting point temperature drawing the sample under the coverslip. Upon cooling, the lower melting point component was then delivered in a similar fashion to create a contact interface between the two samples. These bimolecular samples were heated at a ramp rate of $2-5{ }^{\circ} \mathrm{C} / \mathrm{min}$ until nearly half of the sample melted and then cooled to $60{ }^{\circ} \mathrm{C}$, a temperature below the eutectic temperature of each sample investigated. The heat-cool cycle was repeated 2-3 times to confirm the observed eutectic region(s) formation. All possible combinations of 3- and 4-substituted diarylamide components (18 racemates and 72 quasiracemates) were processed using the video-assisted hot stage technique with micrographs for each system provided in Section S2.

\subsection{Single Crystal X-ray Crystallography}

Crystallographic details of the fourteen crystal structures included in this study of diarylamide racemates and quasiracemates are summarized in Table S1 of the Supplementary Materials. X-ray data were collected using Bruker APEX II CCD or D8 Venture diffractometers (Bruker AXS, Madison, WI, USA) using phi and omega scans with graphite monochromatic Cu Mo $K \alpha(\lambda=1.54178 \AA)$ radiation. Data sets were corrected for Lorentz and polarization effects as well as absorption. The criterion for observed reflections is $I>2 \sigma(I)$. Lattice parameters were determined from least-squares analysis and reflection data. Empirical absorption corrections were applied using SADABS [35]. Structures were solved by direct methods and refined by full-matrix least-squares analysis on $F^{2}$ using X-Seed [36], equipped with SHELXT [37]. All non-hydrogen atoms were refined anisotropically by full-matrix least-squares on $F^{2}$ using the SHELXL [38] program. Hydrogen atoms attached to the nitrogen atoms were located in difference Fourier synthesis and refined isotropically with independent $\mathrm{N}-\mathrm{H}$ distances or restrained to $0.85(2) \AA$. The remaining hydrogen atoms were included in idealized geometric positions with $U_{i s o}=1.2 U_{e q}$ of the atom to which they are attached $\left(U_{i s o}=1.5 U_{e q}\right.$ for methyl groups). Molecular configurations were compared to both the known chirality of the methylbenzylamine and estimated 
Flack parameters [39], and where applicable, atomic coordinates were inverted to achieve correct structural configurations. Hydrogen bond parameters are given in Table S2.

\subsection{Differential Scanning Calorimetry}

Differential scanning calorimetry (DSC) measurements were performed using a TA DSC 25 calorimeter (TA Instruments, New Castle, DE, USA). Samples of rac-H, rac-3-F, $(R)-\mathrm{H} \cdot(S)-3-\mathrm{F}$, rac-3-Cl, rac-3-Me, $(R)-3-\mathrm{Cl} \cdot(S)-4-\mathrm{Me}$, rac-3-CF 3 , rac-3-Br, $(R)-3-\mathrm{CF}_{3} \cdot(S)-3-\mathrm{Br}$, rac-4-F, $(R)-\mathrm{H} \cdot(S)-4-\mathrm{F}$, rac-4-Me, rac-4-NO ${ }_{2},(R)-4-\mathrm{Me} \cdot(R)-4-\mathrm{NO}_{2}$, rac-4-Br, and rac-4-OMe, $(R)-4-\mathrm{Br} \cdot(S)-4-\mathrm{OMe}$ were heated from $60^{\circ} \mathrm{C}$ to $10^{\circ} \mathrm{C}$ above the melting point of the sample at rate of $5{ }^{\circ} \mathrm{C} / \mathrm{min}$. The samples were then cooled to $60^{\circ} \mathrm{C}$ at a rate of $10^{\circ} \mathrm{C} / \mathrm{min}$ to induce recrystallization, and the heat-cool cycle was repeated 2-3 times to confirm the observed thermal events. Samples of 1-3 milligrams were sealed in a Tzero aluminum pan, and the heat flow was measured as a function of temperature using a reference pan.

\subsection{Lattice Energy Calculations}

Crystal lattice energies were determined using the residue-to-residue contact approach via the program Crystal Explorer (ver. 21.5) [40], equipped with Gaussian16 [41]. The Crystal Explorer software, using the B3LYP/6-31G(d,p) interaction energies, was used to calculate lattice energies ( $E$ Latt) for the seventeen unique systems studied by DSC methods (i.e., rac-H, rac-3-F, (R)-H·(S)-3-F, rac-3-Cl, rac-3-Me, (R)-3-Cl-(S)-4-Me, rac-3-CF 3 , rac-3-Br, $(R)-3-\mathrm{CF}_{3} \cdot(S)-3-\mathrm{Br}$, rac-4-F, $(R)-\mathrm{H} \cdot(S)-4-\mathrm{F}$, rac $-4-\mathrm{Me}$, rac-4-NO ${ }_{2},(R)-4-\mathrm{Me} \cdot(R)-4-\mathrm{NO}_{2}$, rac-4$\mathrm{Br}$, rac-4-OMe, $(R)-4-\mathrm{Br} \cdot(S)-4-\mathrm{OMe})$. Molecular assemblies were first constructed using a cluster radius of $10 \AA$ with the lattice energies then computed by direct summation of interaction energies (i.e., electrostatic, dispersion, polarization, and repulsion) with the central molecule included in the cluster. Overall, ELatt values for $Z^{\prime}>1$ structures were determined by weighting the component energies using the occupancy factors determined from crystallographic refinements.

\subsection{Molecular Volume and Shape Difference Determinations}

Molecular volumes were determined using atomic coordinates retrieved as crystallographic data from the CDC Cambridge Structural Database [42]. Each set of initial fractional coordinates were converted to cartesian coordinates (pdb format) using the XSeed software platform. The volume $\left(V_{\mathrm{vdW}}\right)$ of a molecule was assessed using a numerical grid approach (Equation (1)). Each atom was represented as a sphere derived from Bondi atomic radii [43] and superimposed onto a 3D grid with a mesh size of $0.1 \times 0.1 \times 0.1 \AA$. $V_{\mathrm{vdW}}$ (molecule) values were then approximated by summing the volume of the grid points that coincide with the molecule space.

$$
V_{\mathrm{vdW}}\left(\AA^{3} / \text { molecule }\right)=(\Delta x)^{3} \cdot n\left(\AA^{3} / \text { molecule }\right)
$$

$\Delta x=$ grid mesh size $\left(\AA^{3}\right)$

$n=$ number of grid points that coincide with the molecule

$$
\% V_{\mathrm{vdW}}(\text { molecule } \mathrm{A})=100 \times \frac{V_{\mathrm{vdW}}(\text { overlap molecules } \mathrm{A} \text { and B })}{V_{\mathrm{vdW}}(\text { molecule } \mathrm{A})}
$$

A structural tool for determining the molecular shape differences of pairs of molecules was constructed using the numerical approximation of spheres approach derived in the preceding section. Pairs of 4-substituted diarylamide molecules were compared using the six carbon atoms of the benzoyl phenyl group as common points to overlay the molecules. The atomic coordinates used for the overlay process in this study were retrieved as the nitro component of the previously reported (R)-4-Me $(S)-4-\mathrm{NO}_{2}$ quasiracemic structure (CSD, reference code ISACUA). This molecule was used as the 4- $\mathrm{NO}_{2}$ entry and as the common molecular framework, coordinate system, and origin to construct the other derivatives (i.e., $\mathrm{H}, \mathrm{F}, \mathrm{Cl}, \mathrm{Me}, \mathrm{Br}, \mathrm{OMe}, \mathrm{I}, \mathrm{CF}_{3}$ ) used in this study. The $4-\mathrm{NO}_{2}$ molecule was modified using 
the program X-Seed [36], and the AFIX and DFIX commands provided in SHELXL [38] allowed the construction of the other functional groups with suitable bond distances and angles. A computer algorithm generated in $\mathrm{C}^{++}[44]$, was then used to overlay and compare all possible pairs of the 4 -substituted diarylamide derivatives ( 45 combinations). Due to the atomic coordinates for each targeted molecule originate from a common molecular framework, the $V_{\mathrm{vdW}}$ (molecule) regions that lack complete overlap relate only to the shape space differences of the functional groups. This approach calculates the relative percent volume overlap $\left(\% V_{\mathrm{vdW}}\right)$ for pairs of diarylamide molecules (Equation (2)).

\section{Results and Discussion}

This study examines the quasiracemic behavior of sets of 3- and 4-substituted diarylamides. Guven that these targeted systems differ systematically by the position and identity of a pendant functional group, it is anticipated that cocrystallizing all possible pairs of enantiomers and quasienantiomers will provide important insight into the molecular recognition process for these systems. This study takes a multi-pronged approach to understanding the supramolecular assembly of quasiracemates by examining the cocrystallization events (hot stage thermomicroscopy and X-ray crystallography) and crystal lattice energies (differential scanning calorimetry and lattice energy calculations). Additionally, this study has developed a practical structural tool that provides a quantitative measure of shape space differences for pairs of 4-substituted diarylamide molecules using an in silico alignment-based approach. While a theme of our quasiracemate has focused on estimating molecular shape and its effects on molecular recognition using group volumes, this approach offers a new strategy and quantitative measure of the structural differences of quasiracemic components that directly relate to molecular shape.

\subsection{Hot Stage Thermomicroscopy}

The hot stage thermomicroscopy approach to analyzing crystallization phenomena dates back to the early 1900 s and has seen a resurgence due to its operational simplicity and depth of information provided from surveying complex crystallization events [45-48]. The experiment typically involves the delivery of milligrams of solid material to the hot stage device equipped with a polarizing microscope. In the case of quasiracemic systems, the pairs of quasienantiomers are melted and crystallized on a glass slide, starting with the higher melting point compound. The outcome of this process is an interface layer that separates the two quasienantiomers. Further heating of this system with video recording allows the capture of important molecular recognition events at this interface region. In the case of successful quasiracemate formation, a new crystalline phase develops at the material interface and is accompanied by two distinct eutectic regions. Support for the quasiracemate crystalline phase can often be achieved by processing the sample with additional heat-cool cycles, where the size of this third phase increases due to the growth of the quasiracemic material.

This study examined the cocrystalline behavior of two isomeric families of diarylamide quasiracemates via hot stage thermomicroscopy. For these sets of compounds, the imposed structural differences of functional group position and identity provided a strategy for examining homologous families of compounds that systematically differ in their shape space. While the primary motivation of this study was to investigate quasiracemic materials and their self-assembly processes, the racemic counterparts also held much interest since their crystal packing patterns often directly relate to the corresponding quasiracemic phase. The hot stage outcomes from several racemates and quasiracemates are provided in Figure 1, with the complete set of hot stage experiments deposited in Section S2 of the Supplementary Materials. The micrographs collected for quasiracemate $(R)-4-\mathrm{Me} \cdot(S)$ $4-\mathrm{NO}_{2}$ show a sequence of images at $123.9^{\circ} \mathrm{C}, 129.8^{\circ} \mathrm{C}$, and $134.6^{\circ} \mathrm{C}$. These snapshots indicate an interface region between the quasienantiomers transforming with heat to give a new crystalline phase. The other systems (i.e., $r a c-4-\mathrm{NO}_{2}, \mathrm{rac}-3-\mathrm{NO}_{2}$, and (R)-3-Me.(S)-3- 
$\mathrm{NO}_{2}$ depicted in Figure 1 show different thermal events, where pairing the components lacks racemate or quasiracemate formation as evidenced by a single eutectic region.

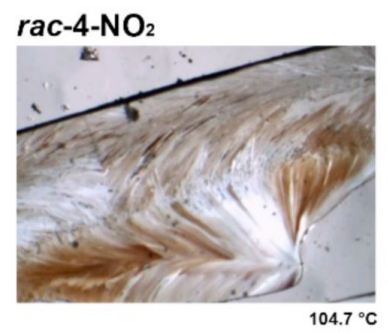

$(S)-4-\mathrm{NO}_{2} \cdot(R)-4-\mathrm{Me}$

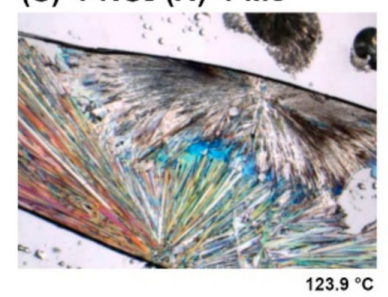

$(S)-3-\mathrm{NO}_{2} \cdot(R)-3-\mathrm{Me}$

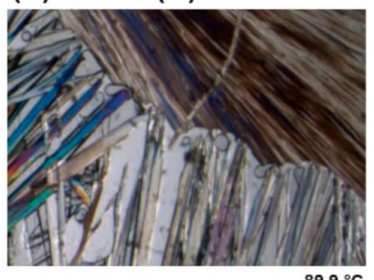

rac-3- $\mathrm{NO}_{2}$

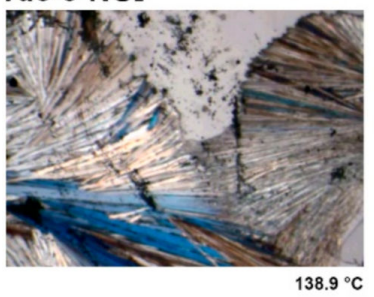

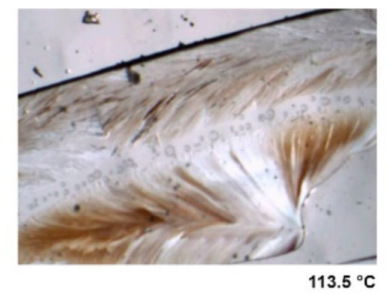

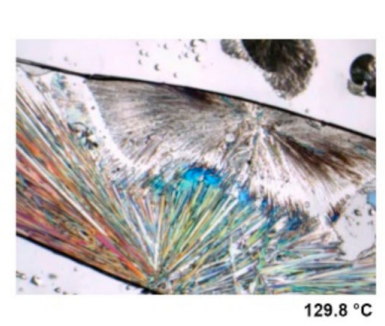

$129.8^{\circ} \mathrm{C}$
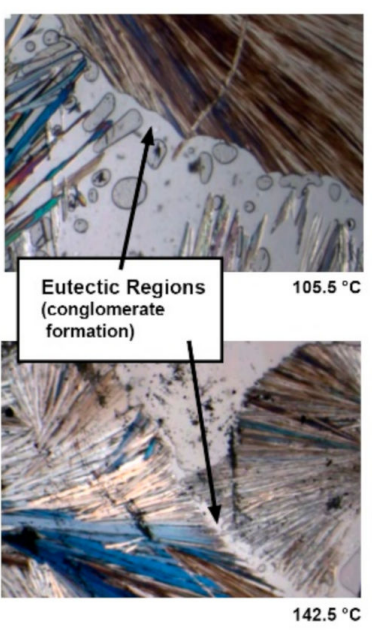
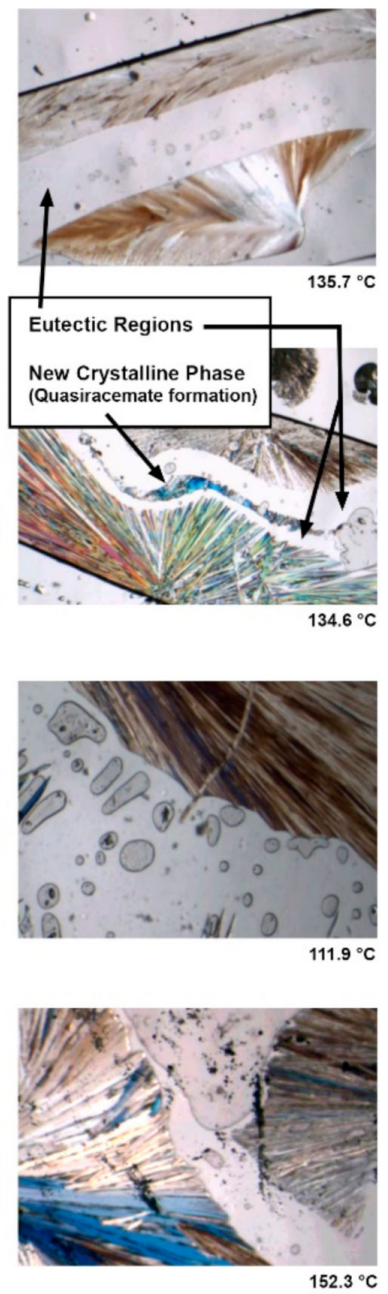

Figure 1. Hot stage micrographs of rac-4- $\mathrm{NO}_{2},(S)-4-\mathrm{NO}_{2} \cdot(R)-3-\mathrm{Me},(S)-3-\mathrm{NO}_{2} \cdot(R)-3-\mathrm{Me}$, and rac-3$\mathrm{NO}_{2}$ showing cocrystallization behavior at various temperatures.

By collecting hot stage data on all possible racemic and quasiracemic combinations, a structural landscape emerged for the two diarylamide systems. This data is summarized in Figure 2 and shows the outcomes from both successful cocrystallization experiments (blue) and those that result in conglomerate formation (grey). In contrast to the previous 2-substituted diarylamides [32], where 34 of 55 entries formed quasiracemates, the 3(18 of 45) and 4-substituted (10 of 45) systems show fewer instances of cocrystal formation. Furthermore, unlike the prior report, not all enantiomeric pairs resulted in racemic compounds. Conglomerate mixtures were observed for the rac-3- $\mathrm{NO}_{2}, \mathrm{rac}-4-\mathrm{NO}_{2}$, racand $4-\mathrm{CF}_{3}$ systems and largely unexpected since racemate formation from small organic molecules has been estimated at $>90 \%[49,50]$. The absence of the nitro and $\mathrm{CF}_{3}$ racemates suggest these samples are less energetically favorable than the crystalline phases of the starting enantiomers. Additionally, crystal growth experiments of many of the racemates and quasiracemates routinely gave thin ill-formed plates that often required multiple attempts. This suggests the interplay of crystal packing energetics likely plays an essential role in the outcomes observed with many of the other cocrystallizations recorded in Scheme 1. The challenge of this molecular recognition issue is also evident from the absence of quasiracemic phases derived from the commonly reported $\mathrm{CH}_{3} / \mathrm{NO}_{2}$ [51], $\mathrm{Cl} / \mathrm{CH}_{3}[52,53]$, and $\mathrm{Cl} / \mathrm{Br}[52-56]$ quasienantiomeric pairs. 

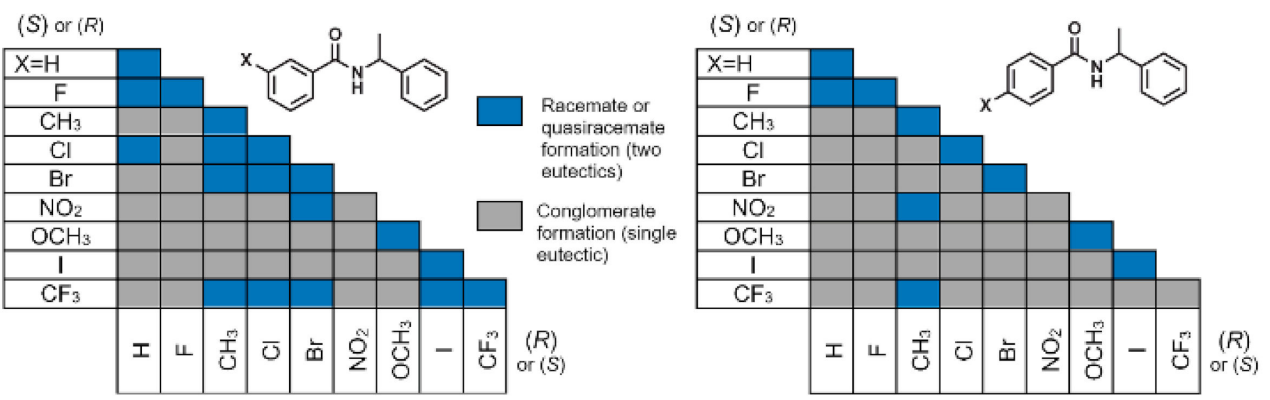

Figure 2. Hot stage thermomicroscopy outcomes from pairing 3-and 4-substituted diarylamide quasienantiomers.

It is interesting to note that while the rac-3- $\mathrm{NO}_{2}$, rac-4- $\mathrm{NO}_{2}$, and rac-4- $-\mathrm{CF}_{3}$ compounds lack cocrystal formation from the melt, several of the generated quasiracemic phases contain the nitro and trifluoromethyl diarylamide components-e.g., $(R)-3-\mathrm{NO}_{2} \cdot(S)-3-\mathrm{Br},(R)-$ $4-\mathrm{NO}_{2} \cdot(S)-4-\mathrm{CH}_{3}$ and $(R)-4-\mathrm{CH}_{3} \cdot(S)-4-\mathrm{NO}_{2}$. The hot stage micrographs of these systems indicate some of the driving force the $\mathrm{Br}$ and $\mathrm{CH}_{3}$ quasienantiomers provide during the cocrystallization process. This supramolecular control modifies the tendency of the nitro and $\mathrm{CF}_{3}$ adducts to form conglomerates by creating an entirely different packing arrangement for these components to assemble. The result is several new quasiracemic phases from the melt, with the $(R)-4-\mathrm{NO}_{2} \cdot(S)-4-\mathrm{CH}_{3}$ system captured as a crystal structure.

\subsection{Crystal Structure Assessment}

The 17 crystal structures included in this study offer important insight into the structural tendencies of two related families of diarylamide compounds (Figures 3 and 4). These structures are grouped into sets of three, where the quasiracemic systems are accompanied by the two related racemates structures for comparison. Data for the rac-4-Me, rac-4- $-\mathrm{NO}_{2}$, and $(R)-4-\mathrm{NO}_{2} \cdot(S)-4-\mathrm{Me}$ systems were retrieved from the CSD as entries ISACUA, ISACOU, and ISACEK, respectively [51].

Each diarylamide system is comprised of a central core constructed from a secondary amide and a stereogenic center connected by adjacent phenyl groups. The practical implication of using one hydrogen-bond donor $(\mathrm{N}-\mathrm{H})$ and one acceptor $(\mathrm{C}=\mathrm{O})$ group is that there are limited modes of molecular association in the crystal to direct diarylamide alignment. Five of the structures exist with $Z^{\prime}=2$, and as expected, each of the 17 crystal structures shows molecules organized via prominent $\mathrm{N}-\mathrm{H} \cdot \mathrm{O}=\mathrm{C}$ contacts. These interactions form C4 graph set motifs $[57,58]$, that extend in the crystal to give 1D hydrogen-bond patterns. These motifs form from infinitely linked diarylamide molecules related by either translation (rac-H, rac-3-F, (R)-H.(S)-3-F, rac-3-Me, rac-3-Br, rac-4-Me, rac-4-NO 2 rac-4-OMe, $(R)-4-\mathrm{Br} \cdot(S)-$ 4-OMe) or glide plane (rac-3-Cl, $(R)-3-\mathrm{Cl} \cdot(R)-3-\mathrm{Me})$, rac-3- $\mathrm{CF}_{3},(R)-3-\mathrm{Br} \cdot(S)-3-\mathrm{CF}_{3}$, rac-4-F, $\left.(R)-\mathrm{H} \cdot(S)-4-\mathrm{F},(R)-4-\mathrm{NO}_{2} \cdot(S)-4-\mathrm{Me}\right)$ symmetry. Additionally, four of the structures exhibit hydrogen/fluorine or phenyl disorder (rac-3-F, $(R)-\mathrm{H} \cdot(S)-3-\mathrm{F}, \mathrm{rac}-3-\mathrm{Cl},(R)-3-\mathrm{Cl} \cdot(S)-3-\mathrm{Me})$ and in five of these structures the $\mathrm{C} 4$ hydrogen bond motif is constructed from heteromeric repeats of alternating enantiomeric or quasienantiomeric components $[(R)-3-\mathrm{Cl} \cdot(S)-3-\mathrm{Me}$, $(R)-3-\mathrm{Br} \cdot(S)-3-\mathrm{CF}_{3},(R)-\mathrm{H} \cdot(S)-4-\mathrm{F}$, rac-4-Me, $\left.(R)-4-\mathrm{NO}_{2} \cdot(S)-4-\mathrm{Me}\right]$.

This set of diarylamide structures lack any notable noncovalent contacts beyond the $\mathrm{N}$ $\mathrm{H} \cdot \cdot \mathrm{O}=\mathrm{C}$ hydrogen-bonds. This observation is somewhat surprising given the diarylamide framework and imposed function group attachments provide additional opportunities to form an array of contacts such as halogen $\cdots$ halogen and phenyl $\cdots X$ interactions. The intended utility of introducing a chemical framework with limited modes of non-bonded contacts was to promote molecular shape in these systems as a dominant structural feature in the assembly of the racemates and quasiracemates. 
RACEMATES

A) rac-3-H

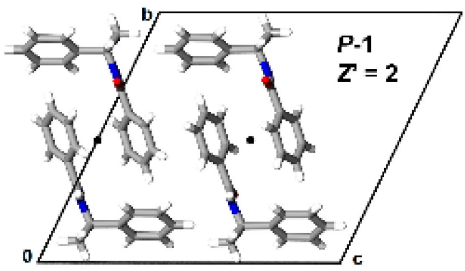

B)

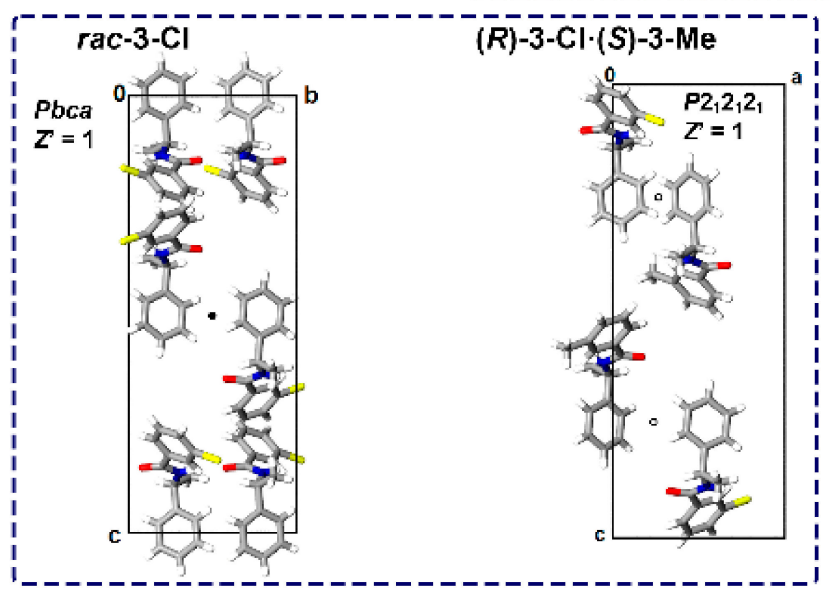

C)

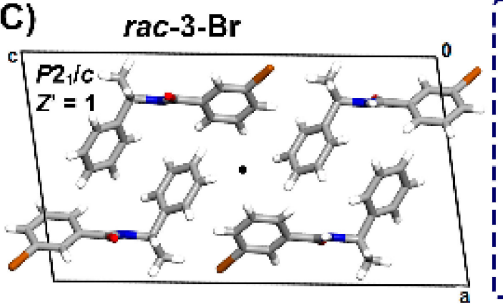

QUASIRACEMATES

RACEMATES
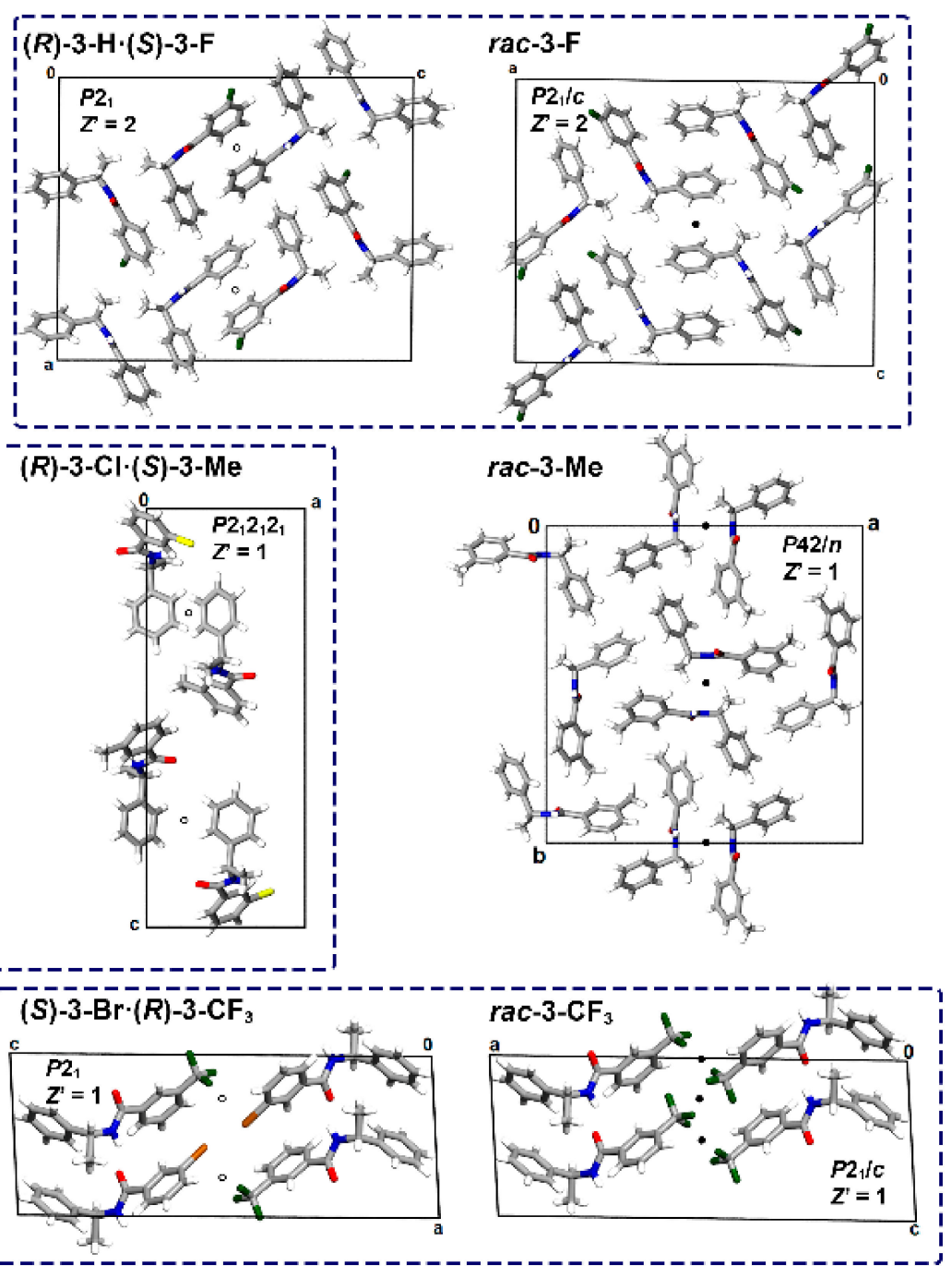

- Inversion Symmetry

a Approximate Inversion

Figure 3. Crystal structures of the racemic and quasiracemic 3-substituted (A) $\mathrm{H} / \mathrm{F},(\mathbf{B}) \mathrm{Cl} / \mathrm{Me}$, and (C) Br/ $\mathrm{CF}_{3}$ diarlyamides. Dashed boxes indicate crystal structures with isostructural relationships.

The quasiracemic crystal structures provided in Figures 3 and 4 organize the quasienantiomeric components with close inversion symmetry relationships. Comparing the packing motifs of these quasiracemic structures to the corresponding racemates shows a high degree of isostructurality [59] with at least one of the racemic structures. As an example, the set of 3-substituted H/F structures (Figure 3, top) shows the quasiracemic components $(R)-\mathrm{H}$ and $(S)-3-\mathrm{F}$ organized in space group $P 2_{1}$ mimicking space group $P 2_{1} / c$. Racemates rac-H and rac-3-F crystallize in space groups $P \overline{1}$ and $P 2_{1} / c$, respectively. The close resemblance of the (R)-H.(S)-3-F and rac-3-F structures extend beyond similar space group settings to include nearly identical packing patterns, unit cell parameters, and crystallographic data sets. Additionally, the H/F disorder pattern observed in rac-3-F also exists in the $(R)-\mathrm{H} \cdot(S)-3-\mathrm{F}$ quasiracemate, further underscoring the feature common to these systems. Close isostructural relationships also exist with many of the other 3and 4-subst $\circledast$ ted quasiracemic systems (i.e., $\mathrm{rac}-3-\mathrm{Cl}$ and $(R)-3-\mathrm{Cl} \cdot(S)-3-\mathrm{Me}, \mathrm{rac}-3-\mathrm{CF}_{3}$ and $(R)-3-\mathrm{Br} \cdot(S)-3-\mathrm{CF}_{3}$, rac-4-F and (R)-H·(S)-4-F, rac-4-OCH 3 and $\left.(R)-4-\mathrm{Br} \cdot(S)-4-\mathrm{CH}_{3}\right)$. 
RACEMATES

A)

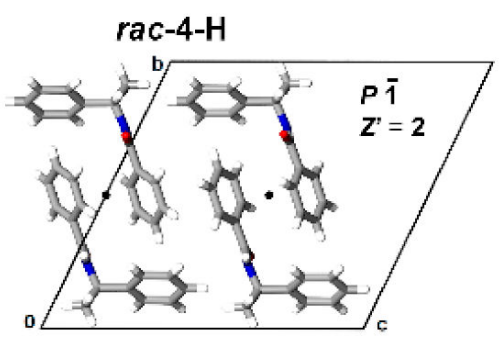

B)

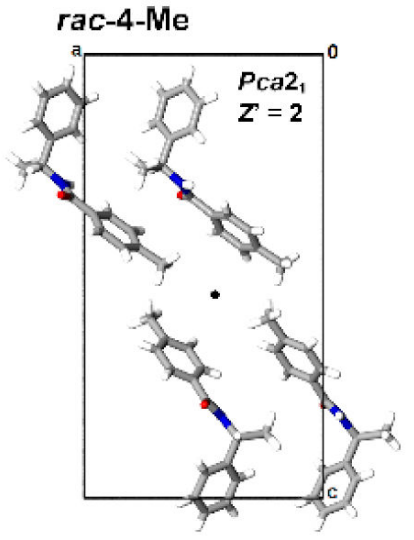

C)

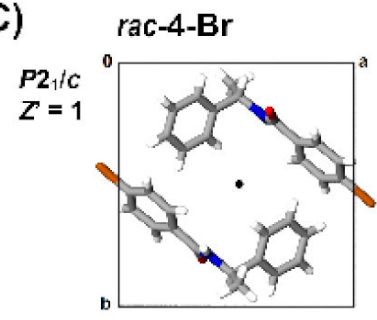

- Inversion Symmetry Element

- Approximate Inversion Symmetry
QUASIRACEMATES

RACEMATES

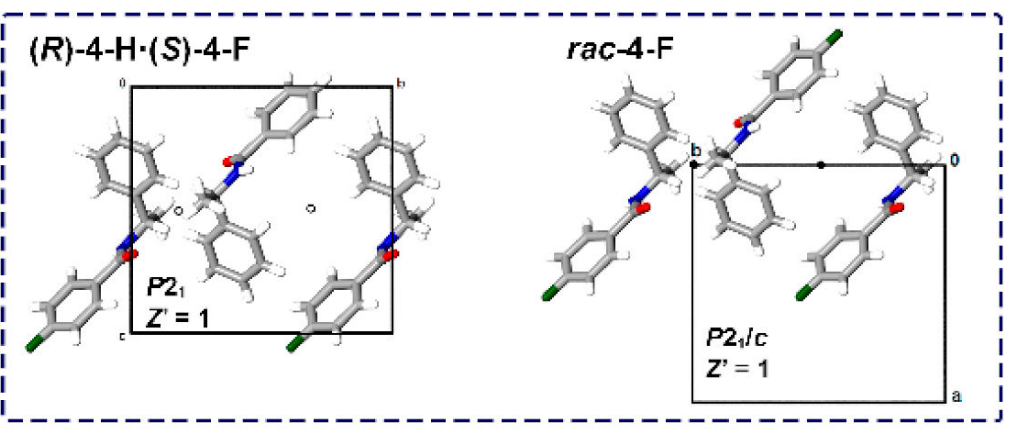

$(R)-4-\mathrm{Me} \cdot(\mathrm{S})-4-\mathrm{NO}_{2}$

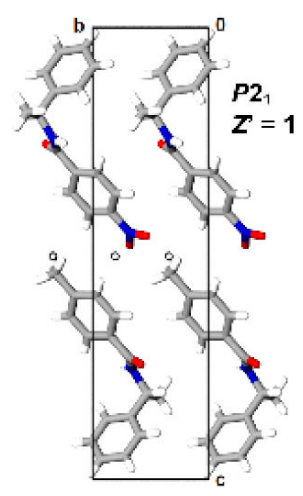

rac- $-4-\mathrm{NO}_{2}$

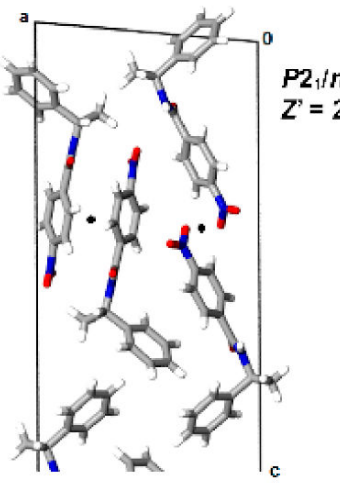

Figure 4. Crystal structures of the racemic and quasiracemic 4-substituted (A) H/F, (B) $\mathrm{Me} / \mathrm{NO}_{2}$, and (C) $\mathrm{Br} / \mathrm{OMe}$ diarlyamides. Dashed boxes indicate crystal structures with isostructural relationships.

Figure 5 highlights Hirshfeld surface fingerprint plots $[40,60]$ for the $(R)-\mathrm{H} \cdot(S)-3-\mathrm{F}$ system. These 2D plots use crystallographic data as input and indicate the immediate environment of the molecule via internal $\left(d_{i}\right)$ and external $\left(d_{e}\right)$ distances from each atom to the Hirshfeld surface. Inspection of the overall patterns generated for the quasiracemate and racemic structures shows sharp spikes positioned at the bottom left of the diagrams representing $\mathrm{O} \cdots \mathrm{H}$ interactions. A second important feature relates to the diffuse or rounded features positioned between these spikes indicating close $\mathrm{H} \cdots \mathrm{H}$ contacts. Together, the shape and size of these patterns provide insight into the structural similarities and variations with the diarylamide systems. The Hirshfeld surface plots of the $(R)-\mathrm{H} \cdot(S)-3-\mathrm{F}$ quasiracemate and racemic counterparts showing several common features such as the signature for $\mathrm{O} \cdots \mathrm{H}$ contacts. This similarity is even more pronounced in the $(R)-\mathrm{H} \cdot(S)-3-\mathrm{F}$ and rac-3-F systems, where the patterns are nearly interchangeable, further supporting the isostructural relationship observed in the crystallographic data. The utility of this 
diagnostic tool as a sensitive contact probe is also apparent when comparing the surface plots of the other crystal structures (Figures S1 and S2). In all but one case, i.e., the (R)-4$\mathrm{Me} \cdot(S)-4-\mathrm{NO}_{2}$ system, there exists a strong correlation between the crystal structures and their fingerprint plots for quasiracemates and the related racemic compounds.
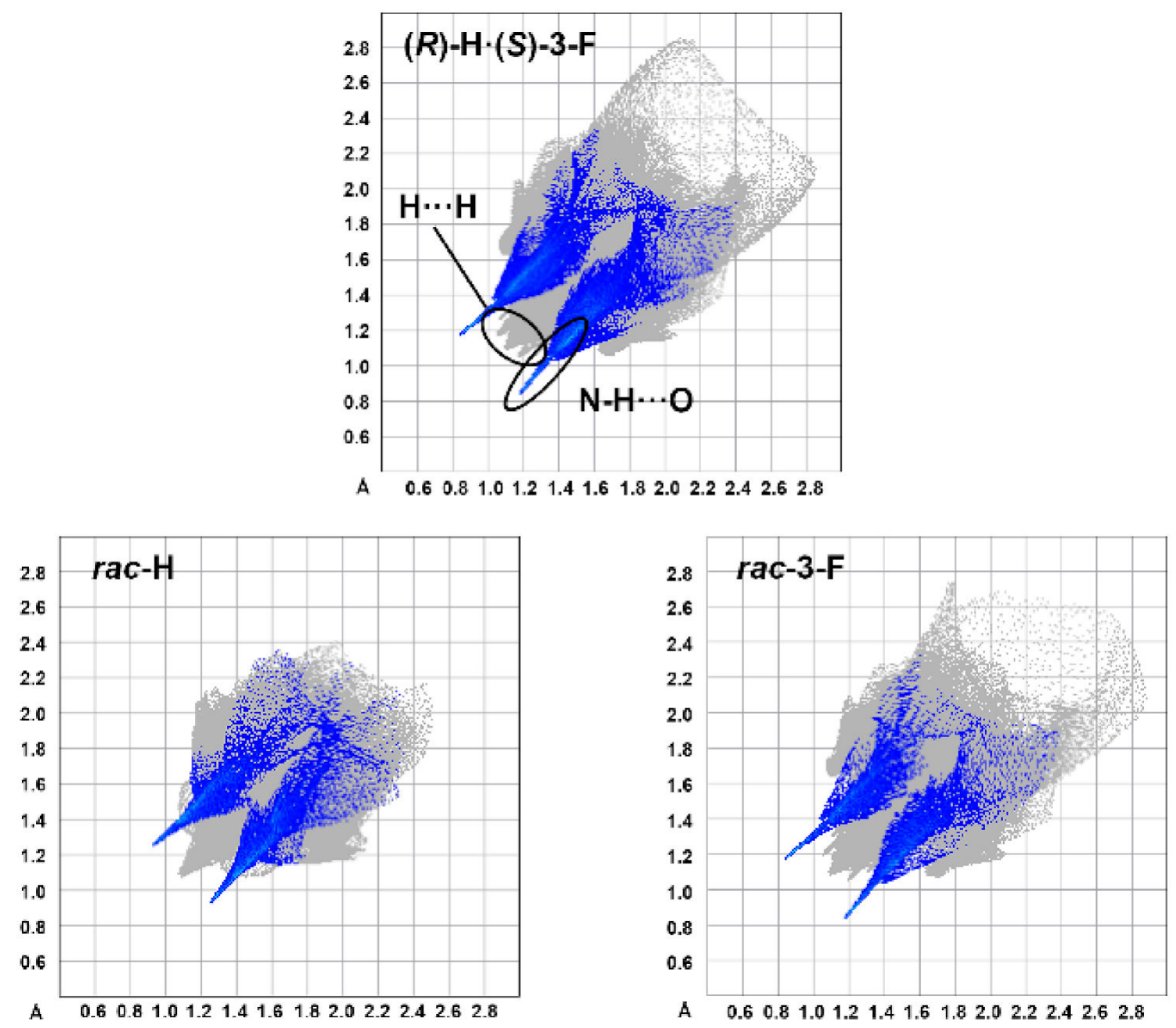

Figure 5. Hirshfeld fingerprint plots for the (R)-H.(S)-3-F quasiracemate and related racemic compounds. Highlighted blue sections indicate the $\mathrm{O} \cdots \mathrm{H}$ contributions to the surface plot.

\subsection{Crystal Lattice Energy Determinations}

Crystal lattice enthalpies were determined using differential scanning calorimetry (DSC) on the set of 3- and 4-substituted diarylamides selected for the crystallographic assessments. As a complementary technique, theoretical calculations of these systems also determined crystal lattice energies using the molecular cluster approach as employed by Crystal Explorer [40] equipped with Gaussian16 ([41], B3LYP/6-31G(d,p)). This computational method utilizes crystallographic data as input and sums the electrostatic, polarization, dispersion, and repulsion contributions to determine lattice energies of the central diarylamide. As shown in Figure 6, the six sets of data consist of both diarylamide racemates and quasiracemates (i.e., $\mathrm{H} \cdot 3-\mathrm{F}, 3-\mathrm{Cl} \cdot 3-\mathrm{Me}, 3-\mathrm{CF}_{3} \cdot 3-\mathrm{Br}, \mathrm{H} \cdot 4-\mathrm{F}$, 4-Me-4- $\mathrm{NO}_{2}$, and 4-Br-4-OMe).

The lattice energies provided in Figure 6 reinforce many of the crystallographic trends observed for each set of diarylamide structures. As one indication of this close relationship, the data corresponding to the H.3-F and H.4-F quasiracemic systems shows a close isostructural relationship of the (R)-H.(S)-3-F quasiracemate and rac-3-F racemate as well as the $(R)-\mathrm{H} \cdot(S)-4-\mathrm{F}$ and rac-4-F pair of compounds. For each family of compounds, the $E_{\text {Latt}}$, melting point, and crystal density data associated with these entries are similar 
and consistent with structures that exhibit closely related crystal packing. Inclusion of the previously reported $(R)-4-\mathrm{CH}_{3} \cdot(\mathrm{S})-4-\mathrm{NO}_{2}$ quasiracemate offers a departure from the quasiracemate systems since the rac-4- $\mathrm{CH}_{3}$ and $\mathrm{rac}-4-\mathrm{NO}_{2}$ racemic structures have fewer common structural and packing features. Even so, despite the differences in functional groups and substitution patterns, the $(R)-4-\mathrm{CH}_{3} \cdot(\mathrm{S})-4-\mathrm{NO}_{2}$ system is isostructural with the $(R)-3-\mathrm{CF}_{3} \cdot(\mathrm{S})-3-\mathrm{Br}$ and $\mathrm{rac}-3-\mathrm{CF}_{3}$ structures, and as expected show comparable $E_{\text {Latt }}$ energies.
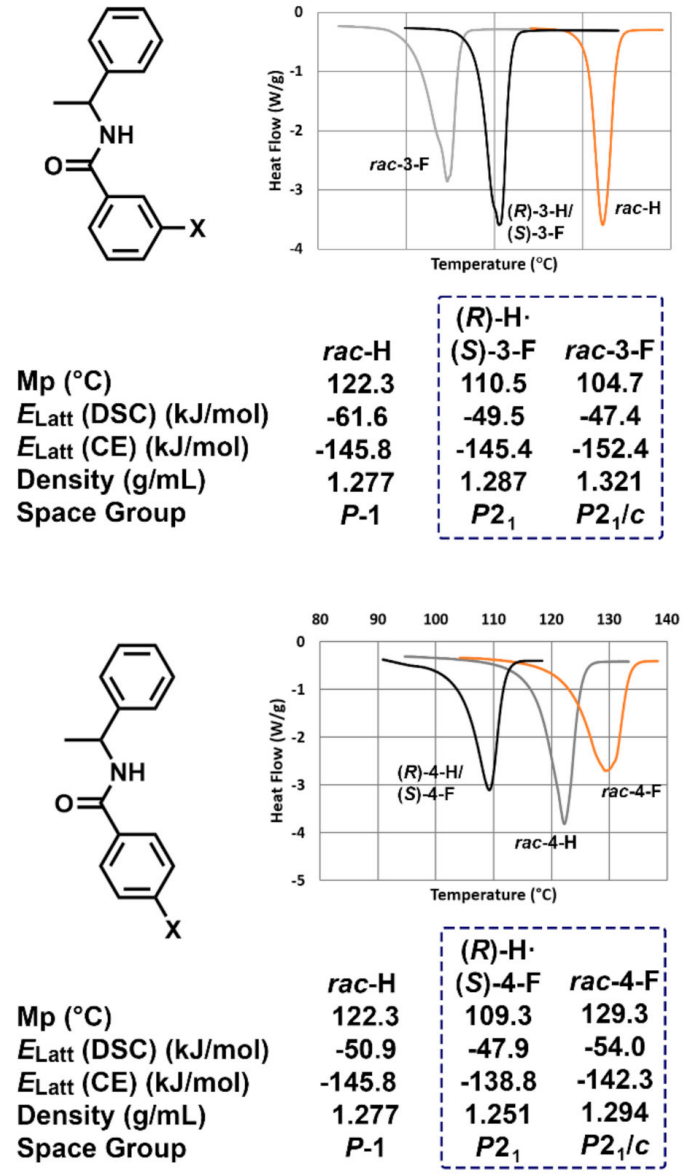
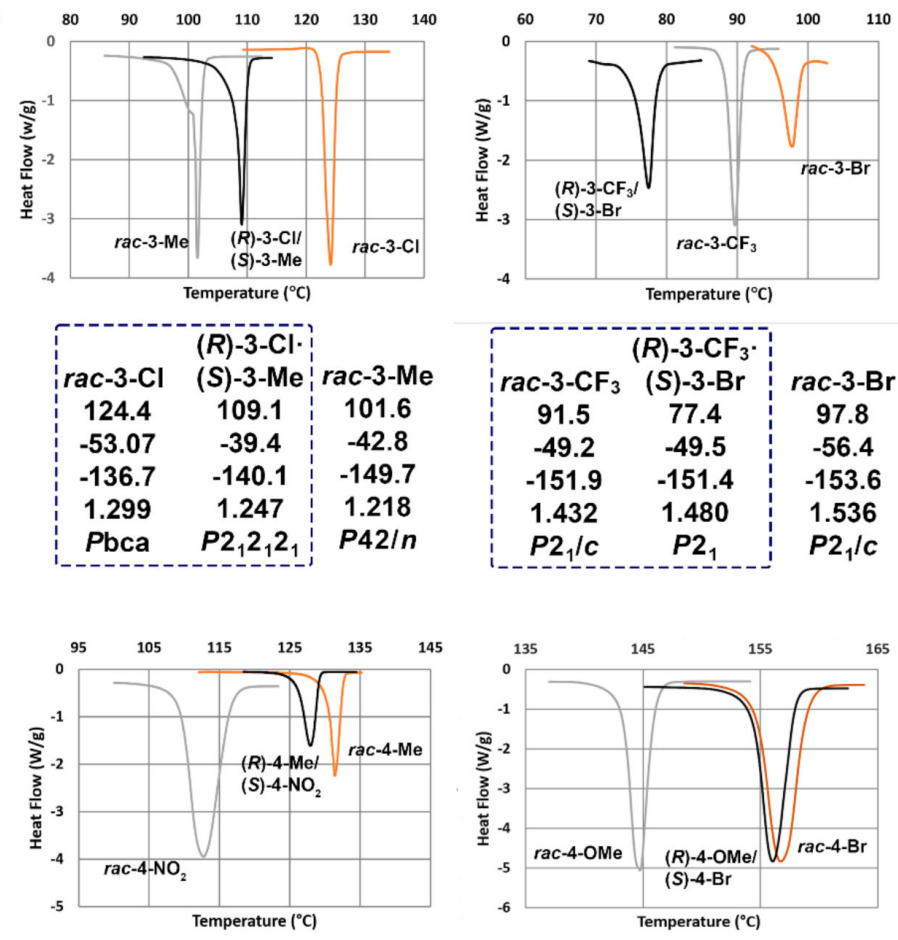

(R)-4-Me.

$\begin{array}{ccc}\text { rac-4-Me } & (S)-4-\mathrm{NO}_{2} & \text { rac-4-NO } \\ 131.4 & 129.1 & 112.6 \\ -55.3 & -52.3 & -56.2 \\ -133.9 & -149.6 & -155.6 \\ 1.155 & 1.286 & 1.375 \\ \text { Pca2 }_{1} & P 2_{1} & P 2_{1} / n\end{array}$

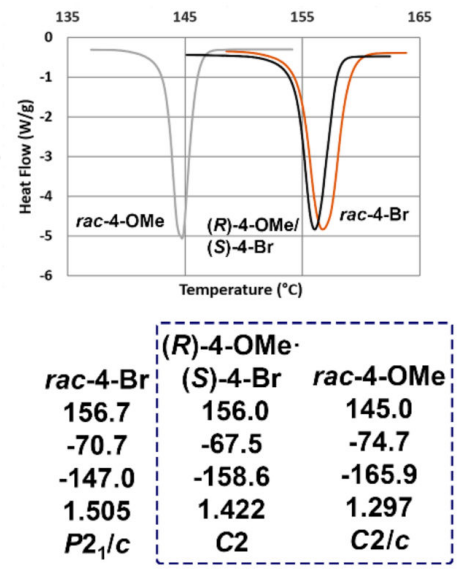

Figure 6. Crystal lattice enthalpies ( $\left.E_{\text {Latt }}\right)$ obtained from differential scanning calorimetry (DSC) data and Crystal Explorer (CE) (B3LYP/6-31G(d,p), Gaussian16), crystal densities and melting point data for 3- and 4-substituted diarylamides.

\subsection{Molecular Volume and Shape Difference Determinations}

An important aspect of this work, and that from our previous studies, focuses on understanding how the spatial properties (size and shape) of quasienantiomers impact the formation of quasiracemic materials. While the use of closely related quasienantiomers can increase the success of cocrystallization, this strategy does not always ensure the expected outcomes. Some of these challenges with predicting quasiracemate formation relate directly to the selection of the molecular framework. Seemingly small changes to molecular structure can significantly impact crystal stabilization, with consequences that alter the landscape of molecular assembly. For example, we recently observed that systematically increasing the size of the molecular scaffold effectively extended the structural boundary for cocrystallization. The shape similarity of pairs of quasienantiomers is another area that further contributes to quasiracemate prediction. Given that the definition of 'similar' when describing quasiracemates is often ambiguous and open to user interpretation, it is important to establish a general method or set of descriptors that adequately describe the property of molecular shape. Computer-aided discovery methods [61-63] and math- 
ematical/geometric descriptors [64-66], have been employed to profile or approximate the properties of molecular shape. Our group has used molecular and functional group volumes with regularity as a first approximation of the molecular shape property $[18,67]$; even so, this approach and those from others do not provide a direct indicator of the topological features of molecules. One indication using volume data oversimplifies molecular shape is that the $\mathrm{OCH}_{3}$ and $\mathrm{NO}_{2}$ substituents possess nearly identical volumes (Scheme 1, 30.3 and $30.2 \AA^{3}$ ) with significantly different geometries (bent and trigonal planar). In this portion of our study, we look at an approach that quantitatively compares the shape space of pairs of compounds using an alignment-based method to calculate the shape similarity of superimposed molecules. By overlaying sets of molecules onto a grid system, the relative percent volume overlap can be determined and ultimately used to advantage to describe the common spatial features of the molecular pair. This technique determines molecular volumes $\left(V_{\mathrm{vdW}}\right)$ as well as the relative percent volume overlap space $\left(\% V_{\mathrm{vdW}}\right)$ for all possible isomeric combinations of the 4-substituted diarylamide system. By mapping the shape space, we hope to provide a diagnostic tool that correlates quasiracemate successes and the shape space of the quasienantiomeric components. Success with this approach is predicated on molecular shape serving as the principal driving force during quasiracemate assembly. As highlighted in the following discussion, the 3- and 4-substituted diarylamide systems lack a strong correlation of the $\% V_{\mathrm{vdW}}$ data to quasiracemate formation likely indicating that other factors significantly impact the molecular recognition process.

Several approaches have been developed to assess molecular shape matching. When considering the crystallographic community, an obvious choice for this task is the structure overlay utility found in the CCDC-Mercury program [68]. This resource provides a practical structural tool to overlay molecules and determine the degree of fit using a root-mean-square difference approach. However, because CCDC-Mercury requires the selection of pairs of related atoms from each molecule, quasienantiomers differing by $\mathrm{CH}_{3}$ and $\mathrm{Cl}$ groups could not be adequately processed using this method. Other approaches allow for the rapid determination of overlap volumes of aligned molecules $[64,66,69,70]$. The technique presented here draws from this previous work using an alignment-based approach specifically encoded for our diarylamide scaffolds with common origins and coordinate systems.

As shown in Figure 7A, intrinsic molecular volumes were determined by considering the atomic contributions superimposed onto a 3D grid system with a mesh size of $0.1 \times$ $0.1 \times 0.1 \AA$ (Equation (1)). This was accomplished by developing a computer algorithm that retrieves atomic coordinates from crystallographic data and then treats atoms as a series of mutually intersecting spheres. $V_{\mathrm{vdW}}$ (molecule) values were determined using Bondi radii [43], for each atom and summing the volume of the grid spaces that coincide with the molecule space. Looking beyond bond types, this strategy simplifies molecules as a collection of spheres for determining molecular volumes. As a first step, a proof-ofconcept was performed to verify the validity of this approach by comparing the $V_{\mathrm{vdW}}$ (Equation (1)) volumes of 81 randomly selected molecules ranging in structure to those previously determined using the TSAR computer program (Oxford Molecular LTD) and the Atomic and Bond Contributions of van der Waals Volume (VABC) approach [71]. Input for these $V_{\mathrm{vdW}}$ (Equation (1)) values consisted of atomic coordinates retrieved from the CSD. The plot provided in Figure 8A compares $V_{\mathrm{vdW}}$ (Equation (1)) volumes to those determined using the $V_{\mathrm{vdW}}$ (TSAR) and $V_{\mathrm{vdW}}$ (VABC) methods. As previously described, the $V_{\mathrm{vdW}}(\mathrm{TSAR})$ values are consistently less than that reported for $V_{\mathrm{vdW}}$ (VABC) [71], with $V_{\mathrm{vdW}}$ (Equation (1)) volumes falling between each of these reported methods. These results show the absolute values between the two sets of data are very close, with 0.981 and 0.968 correlation coefficients, respectively. Additionally, as expected, a comparison of the difference in $V_{\mathrm{vdW}}$ (Equation (1)) and the TSAR and VABC volumes show a more significant variation in $\Delta V_{\mathrm{vdW}}$ with increasing molecular weight. 
A)

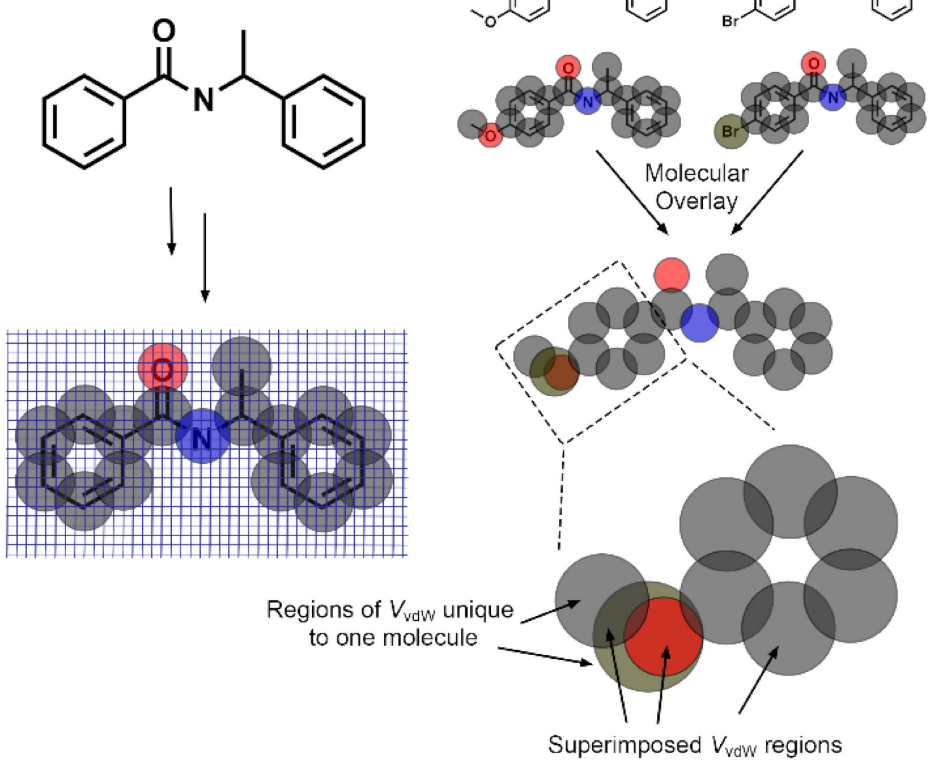

Figure 7. Strategies to determine (A) molecular volumes $\left(V_{\mathrm{vdW}}\left(\AA^{3} /\right.\right.$ molecule $\left.)\right)$ from atomic spheres and grid points and (B) $\Delta V_{\mathrm{vdW}}$ for pairs of diarylamides. Hydrogen atoms were omitted for clarity.
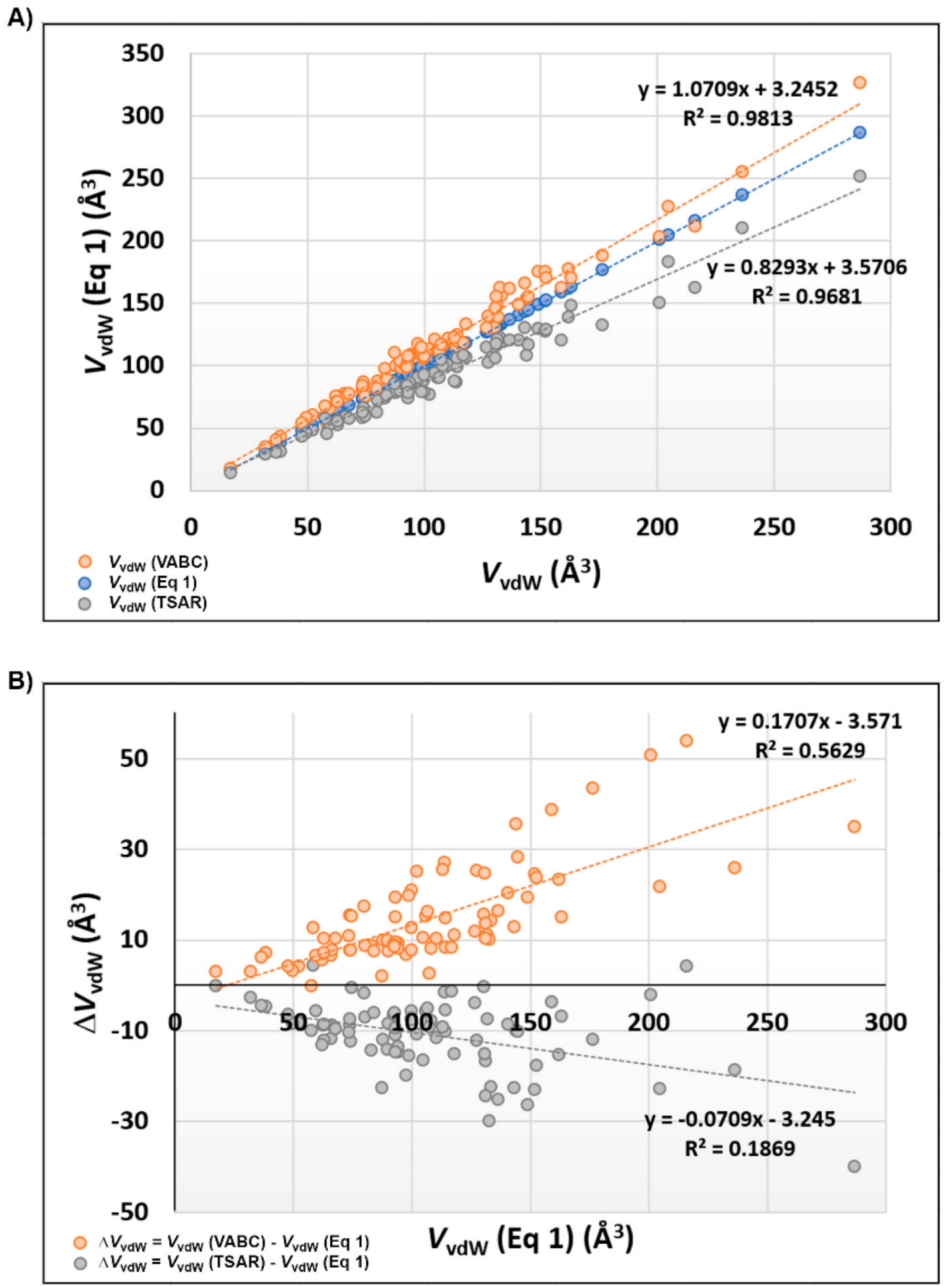

Figure 8. Plots of (A) $V_{\mathrm{vdW}}$ and (B) $\Delta V_{\mathrm{vdW}}$ data determined from $V_{\mathrm{vdW}}$ (Equation (1)) and previously reported $V_{\mathrm{vdW}}$ (TSAR) and $V_{\mathrm{vdW}}(\mathrm{VABC})$. 
This approach for determining molecular volumes was adopted as part of a diagnostic tool for comparing the shape space of pairs of molecules. Atomic coordinates from 4$\mathrm{NO}_{2}$ were retrieved from ISACUA and modified to construct the other 4-substituted diarylamide derivatives $\left(\mathrm{H}, \mathrm{Me}, \mathrm{Cl}, \mathrm{Br}, \mathrm{NO}_{2}, \mathrm{OCH}_{3}, \mathrm{I}\right.$, and $\left.\mathrm{CF}_{3}\right)$ to maximize the overlap of molecules. Additionally, constructing a family of related molecules with a common chemical framework, coordinate system, and origin allowed the rapid calculation of the overlap volumes of aligned molecules (Figure 7B). Though this application is specific to the diarylamide molecular framework, conceptually, the method could be adapted to other chemical systems of interest.

Figure $9 \mathrm{~A}$ shows the $V_{\mathrm{vdW}}$ (molecule) and $\% V_{\mathrm{vdW}}$ overlap data for the set of 4-substituted diarylamides, with information ordered to match the list provided in Scheme 1. The observed trend of $V_{\mathrm{vdW}}$ (molecule) values closely correlates to the $V_{\text {functional group }}$ except for the $\mathrm{NO}_{2}$ group. In this case, the use of single Bondi radii values for each atom type likely overestimates the size of the zwitterionic nitro oxygen atoms. The remaining data provided in the staircase plot relate to the relative percent overlay volumes for pairs of molecules. This overlap volume information was determined by considering the regions distinct to each molecule and those producing molecular overlap (Figure 7B). Each of the 45 data cells in Figure $9 \mathrm{~A}$ contains two sets of $\% V_{\mathrm{vdW}}$ data corresponding to the relative percent volume overlap of each molecule. As an example, the 4-Me/4-F diarylamide combination indicates $99.6 \%$ of the $4-\mathrm{F}$ molecule overlapped by $4-\mathrm{Me}$, and $4-\mathrm{F}$ overlaps $94.6 \%$ of the volume of $4-\mathrm{Me}$. The top diagonal edge of data relates to processing sets of identical molecules, and as expected, the outcomes from these calculations show 100\% overlap of molecular volumes. The remaining data quantify the relative percent volume overlaps for all possible combinations of the nine diarylamide derivatives-36 data cells. The data shows this method is quite sensitive to the spatial features of each set of compounds. Similar to the trends observed for the molecular volume calculations, the $\% V_{\mathrm{vdW}}$ values follow an expected pattern related to the size and shape of the functional groups. When keeping the shape constant, as with the $\mathrm{H}, \mathrm{F}, \mathrm{Cl}, \mathrm{Br}$, and I derivatives, the $\% V_{\mathrm{vdW}}$ data changes incrementally. The extensive use of the $\mathrm{Cl} / \mathrm{Br}$ pair in quasiracemate studies is intuitive given their similar shapes and group volumes. As expected, their calculated $\% V_{\mathrm{vdW}}$ values $(99.7 \% / 96.9 \%)$ show a high degree of volume overlap and shape similarity. To provide perspective, calculating $\% V_{\mathrm{vdW}}$ for the $\mathrm{H} / \mathrm{CF}_{3}$ pair gave $99.2 \%$ and $81.2 \%$, where the smaller value represents the lower limit of $\% V_{\mathrm{vdW}}$ calculations for these diarylamide molecules. The cases that form 4-substituted diarylamide quasiracemates suggest that a $\% V_{\mathrm{vdW}}$ value of $\sim 90 \%$ is needed to consider successful quasiracemate formation. If this method were applied to larger molecular frameworks, this threshold would change since the imposed functional group differences would have a lesser contribution to the overall space shape of the molecules.

This study also considered the 2- [32] and 3-substituted diarylamide frameworks. While the data in Figure 9A were derived using the 4-substituted system, the use of a common framework suggests the same $\% V_{\mathrm{vdW}}$ values can be applied to the other isomeric systems where the difference is only the functional group positions on the benzoyl moiety. The 3-substituted system experiences limited success, and similar to the 4-substituted system shows trends in quasiracemate formation that lack direct adherence to the topological features of the molecules. Given that the 2-substituted diarylamides follow a logical progression of increasing functional group shape space linked to quasiracemate success, it is in these cases that the $\% V_{\mathrm{vdW}}$ overlap data can be most helpful. From inspection of Figure 9B (right), the data reveals 26 of the 45 entries result in racemates or quasiracemates. As previously reported, the methoxy exception can be explained by a difference in molecule shape due to intramolecular hydrogen bonding. The remaining data show success from combining the $\mathrm{CH}_{3}, \mathrm{Cl}, \mathrm{Br}, \mathrm{NO}_{2}, \mathrm{I}$, and $\mathrm{CF}_{3}$ components with cocrystallization failures related to the smaller $\mathrm{H}$ and $\mathrm{F}$ components. When considering the crystal landscape of this system, it seems that $\% V_{\mathrm{vdW}} \sim 90 \%$ is the threshold for quasiracemate formation corresponding to the molecular pair with the most significant spatial difference $\left(\mathrm{CH}_{3} / \mathrm{CF}_{3}\right)$. 
It should be mentioned that the $\mathrm{CH}_{3} / \mathrm{CF}_{3}$ pairing and $\% V_{\mathrm{vdW}}$ threshold estimates for the 4- and 2-substituted diarylamide are consistent and potentially offer threshold critical insight to the structural boundary required for quasiracemate formation. Additional work is needed to examine this threshold further using a variety of chemical systems.

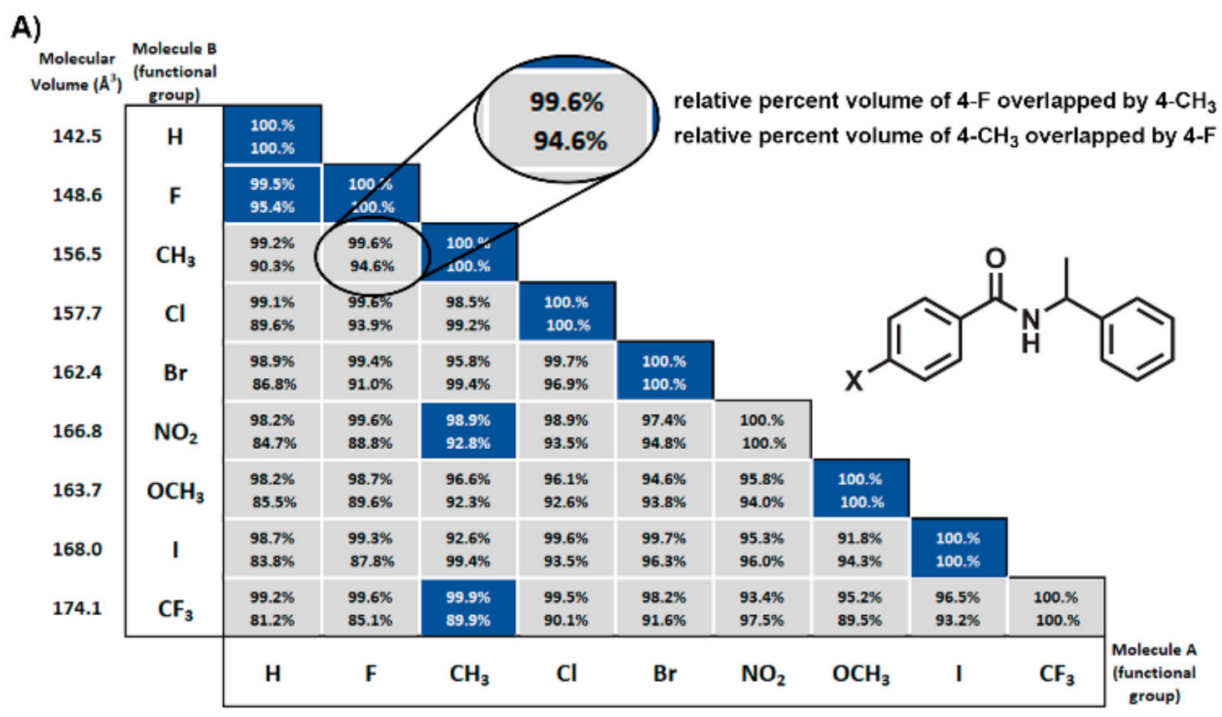

B)
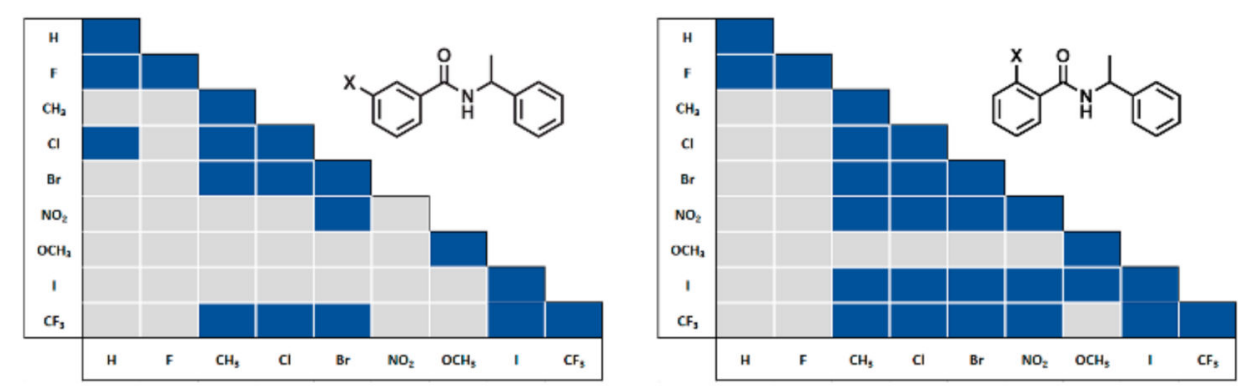

Figure 9. (A) Molecular volumes and relative percent volume overlap ( $\left.\% V_{\mathrm{vdW}}\right)$ for all possible quasienantiomeric pairs sets of 4-substituted diarylamides. Blue (racemate or quasiracemate formation) and grey (conglomerate formation) entries indicate cocrystallization outcomes from the melt. (B) results from cocrystallizing the 3- and 2-substituted diarylamide systems from the melt. (2-substituted diarylamide data taken from [32]).

This structural tool offers a new approach for mapping the shape space of quasienantiomeric components. When applied to families of related compounds where quasiracemate successes and failures are known, a structural boundary based on spatial properties of molecules can emerge. Additionally, by providing a numerical approximation of the difference in molecular shape for a pair of compounds, the relationship of molecular framework and functional group selection can be implemented during the design stage of experiments. The low success rates for the 3- and 4-substituted diarylamide systems suggest many factors contribute to quasiracemate formation beyond just the use of complementary molecular shapes. While these outcomes underscore the importance of the crystal growth process and crystal lattice energetics, this approach assesses the topological differences of pairs of compounds and contributes to developing the next generation of structural tools capable of codifying the factors responsible for molecular assembly. As a future extension of this work, constructing a platform that accommodates alignment-free molecular shape comparisons unrelated to molecular framework would provide a versatile tool for probing the shape space of pairs of molecules that would benefit other applications in the material sciences beyond the study of quasiracemates. 


\section{Conclusions}

We describe the crystal chemistry of two families of 3- and 4-substituted diarylamides where the pendant functional groups differ systematically in shape and size. Outcomes from the cocrystallization (hot stage thermomicroscopy and X-ray crystallography) and crystal lattice energy (differential scanning calorimetry and lattice energy calculations) determinations for many of these systems and their racemic counterparts showed the role molecular shape plays in the molecular recognition process. The low success rates of quasiracemate formation via the hot stage experiments suggest crystal lattice energetics during the molecular assembly compete with the close packing achieved from assembling the complementary shapes of quasienantiomers. This study also developed a computer algorithm using an alignment-based molecular shape method for approximating the degree of isostructurality of pairs of quasienantiomers that could be useful for predicting quasiracemate success.

Supplementary Materials: The following are available online at https:/ /www.mdpi.com/article/10 .3390/ cryst11121596/s1, Section S1, Experimental Details; Section S2, Hot Stage Thermomicroscopy; Section S3, X-ray Crystallography; Section S4, Hirshfeld Surface Analyses; and Section S5, Molecular Volume and Shape Difference Determinations. Table S1: Crystallographic Data for Diarylamide Quasiracemates and Racemates, Table S2: Hydrogen Bond Parameters for Diarylamide Crystal Structures, Figure S1: Hirshfeld fingerprint plots for the (A) rac-H, (R)-H.(S)-3-F, rac-3-F, (B) rac-3-Cl, $(R)-3-\mathrm{Cl} \cdot(S)-3-\mathrm{Me}$, rac-3-Me, and $(\mathrm{C}) \mathrm{rac}-3-\mathrm{CF}_{3},(R)-3-\mathrm{CF}_{3} \cdot(S)-3-\mathrm{Br}$, rac-3-Br 3-substituted diarylamide systems highlighting $\mathrm{H} \cdots \mathrm{H}$ and $\mathrm{O} \cdots \mathrm{H}$ contacts. Highlighted blue regions indicate $\mathrm{O} / \mathrm{H}$ contributions to the surface, Figure S2: Hirshfeld fingerprint plots for the (A) rac-H, (R)-H.(S)-4-F, rac-4-F, (B) rac-4$\mathrm{Me},(R)-4-\mathrm{Me} \cdot(S)-4-\mathrm{NO}_{2}$, rac-4-NO $\mathrm{N}_{2}$, and $(\mathrm{C})$ rac-4-Br, $(R)-4-\mathrm{Br} \cdot(S)-3-\mathrm{OMe}$, rac-4-OMe 4-substituted diarylamide systems highlighting $\mathrm{H} \cdots \mathrm{H}$ and $\mathrm{O} \cdots \mathrm{H}$ contacts. Highlighted blue regions indicate $\mathrm{O} / \mathrm{H}$ contributions to the surface.

Author Contributions: Conceptualization, K.A.W. and D.R.S.; methodology, K.A.W. and D.R.S.; software, A.Y.; formal analysis, K.A.W. and D.R.S.; investigation, A.K.B., D.J.B., J.P.B., A.R.G., S.E.P., J.M.S., M.M.V., A.K.S., A.Y. and K.A.W.; writing-original draft preparation, K.A.W.; writing-review and editing, K.A.W. and D.R.S.; visualization, K.A.W.; supervision K.A.W. and D.R.S., project administration K.A.W. and D.R.S. All authors have read and agreed to the published version of the manuscript.

Funding: This work was generously supported by the National Science Foundation (DMR1904651 and CHE1827313) and a Hugh Johnston Interdisciplinary Research Grant from Whitworth University.

Institutional Review Board Statement: Not applicable.

Informed Consent Statement: Not applicable.

Data Availability Statement: Crystallographic data has been deposited at https:/ /ccdc.cam.ac.uk/ . CCDC 2111816-2111829.

Acknowledgments: The authors wish to thank A. L. Rheingold (University of California San Diego) for key crystallographic contributions to this study.

Conflicts of Interest: The authors declare no conflict of interest.

\section{References}

1. Fredga, A. Quasiracemic compounds and their use for studying the configuration of optically active compounds. Bull. De La Soc. Chim. Fr. 1973, 1, 173-182.

2. Zhang, Q.; Curran, D.P. Quasienantiomers and quasiracemates: New tools for identification, analysis, separation, and synthesis of enantiomers. Chem. Eur. J. 2005, 11, 4866-4880. [CrossRef] [PubMed]

3. Grabowski, S.J. Understanding Hydrogen Bonds: Theoretical and Experimental Views; Royal Society of Chemistry: Cambridge, UK, 2021.

4. Herschlag, D.; Pinney, M.M. Hydrogen Bonds: Simple after All? Biochemistry 2018, 57, 3338-3352. [CrossRef] [PubMed]

5. Liu, G.; Wei, S.-H.; Zhang, C. Review of the Intermolecular Interactions in Energetic Molecular Cocrystals. Cryst. Growth Des. 2020, 20, 7065-7079. [CrossRef] 
6. Remsing, R.C.; Klein, M.L. Halogen bond structure and dynamics from molecular simulations. J. Phys. Chem. B 2019, 123, 6266-6273. [CrossRef]

7. Mir, N.A.; Dubey, R.; Desiraju, G.R. Strategy and methodology in the synthesis of multicomponent molecular solids: The quest for higher cocrystals. Acc. Chem. Res. 2019, 52, 2210-2220. [CrossRef] [PubMed]

8. Cavallo, G.; Metrangolo, P.; Milani, R.; Pilati, T.; Priimagi, A.; Resnati, G.; Terraneo, G. The halogen bond. Chem. Rev. 2016, 116, 2478-2601. [CrossRef]

9. Scilabra, P.; Terraneo, G.; Resnati, G. The Chalcogen Bond in Crystalline Solids: A world parallel to halogen bond. Acc. Chem. Res. 2019, 52, 1313-1324. [CrossRef]

10. Liao, W.-Q.; Tang, Y.-Y.; Li, P.-F.; You, Y.-M.; Xiong, R.-G. Competitive halogen bond in the molecular ferroelectric with large piezoelectric response. J. Am. Chem. Soc. 2018, 140, 3975-3980. [CrossRef]

11. Zhao, Y.; Sarnello, E.S.; Robertson, L.A.; Zhang, J.; Shi, Z.; Yu, Z.; Bheemireddy, S.R.; Li, T.Y.Z.; Assary, R.S.; Cheng, L.; et al. Competitive Pi-Stacking and H-Bond piling increase solubility of heterocyclic redoxmers. J. Phys. Chem. B 2020, 124, 10409-10418. [CrossRef]

12. ̌ezáč, J.; Hobza, P. Benchmark calculations of interaction energies in noncovalent complexes and their applications. Chem. Rev. 2016, 116, 5038-5071. [CrossRef]

13. Biedermann, F.; Schneider, H.-J. Experimental binding energies in supramolecular complexes. Chem. Rev. 2016, 116, 5216-5300. [CrossRef]

14. Taylor, C.R.; Day, G.M. Evaluating the energetic driving force for cocrystal formation. Cryst. Growth Des. 2018, 18, 892-904. [CrossRef] [PubMed]

15. Gavezzotti, A. Collective variables for the simulation of crystallization of organic compounds: Some case studies. Isr. J. Chem. 2021, 61, 498-506. [CrossRef]

16. Spackman, M.A. How reliable are intermolecular interaction energies estimated from topological analysis of experimental electron densities? Cryst. Growth Des. 2015, 15, 5624-5628. [CrossRef]

17. Görbitz, C.H.; Dalhus, B.; Day, G.M. Pseudoracemic amino acid complexes: Blind predictions for flexible two-component crystals. Phys. Chem. Chem. Phys. 2010, 12, 8466-8477. [CrossRef]

18. Craddock, D.E.; Parks, M.J.; Taylor, L.A.; Wagner, B.L.; Ruf, M.; Wheeler, K.A. Increasing the structural boundary of quasiracemate formation: 4-substituted naphthylamides. CrystEngComm 2021, 23, 210-215. [CrossRef]

19. Pinter, E.N.; Cantrell, L.S.; Day, G.M.; Wheeler, K.A. Pasteur's tartaramide/malamide quasiracemates: New entries and departures from near inversion symmetry. CrystEngComm 2018, 20, 4213-4220. [CrossRef]

20. Wells, R.G.; Sahlstrom, K.D.; Wheeler, K.A. Amino acid hydrogen oxalate quasiracemates—Sulfur containing side chains. CrystEngComm 2021, 23, 8061-8070. [CrossRef]

21. Kreitler, D.F.; Mortenson, D.E.; Forest, K.T.; Gellman, S.H. Effects of single $\alpha$-to- $\beta$ residue replacements on structure and stability in a small protein: Insights from quasiracemic crystallization. J. Am. Chem. Soc. 2016, 138, 6498-6505. [CrossRef]

22. Yan, B.; Ye, L.; Xu, W.; Liu, L. Recent advances in racemic protein crystallography. Bioorganic Med. Chem. 2017, 25, 4953-4965. [CrossRef]

23. Mandal, K.; Dhayalan, B.; Avital-Shmilovici, M.; Tokmakoff, A.; Kent, S.B.H. Crystallization of enantiomerically pure proteins from quasi-racemic mixtures: Structure determination by X-ray diffraction of isotope-labeled ester insulin and human insulin. ChemBioChem 2016, 17, 421-425. [CrossRef]

24. Kurgan, K.W.; Kleman, A.F.; Bingman, C.A.; Kreitler, D.F.; Weisblum, B.; Forest, K.T.; Gellman, S.H. Retention of native quaternary structure in racemic melittin crystals. J. Am. Chem. Soc. 2019, 141, 7704-7708. [CrossRef]

25. Smets, M.M.H.; Kalkman, E.; Krieger, A.; Tinnemans, P.; Meekes, H.; Vlieg, E.; Cuppen, H.M. On the mechanism of solid-state phase transitions in molecular crystals-The role of cooperative motion in (quasi)racemic linear amino acids. IUCrJ 2020, 7 , 331-341. [CrossRef] [PubMed]

26. Hasell, T.; Little, M.A.; Chong, S.Y.; Schmidtmann, M.; Briggs, M.E.; Santolini, V.; Jelfs, K.E.; Cooper, A.I. Chirality as a tool for function in porous organic cages. Nanoscale 2017, 9, 6783-6790. [CrossRef] [PubMed]

27. Dang, B.; Shen, R.; Kubota, T.; Mandal, K.; Bezanilla, F.; Roux, B.; Kent, S.B.H. Inversion of the side-chain stereochemistry of indvidual thr or ile residues in a protein molecule: Impact on the folding, stability, and structure of the shk toxin. Angew. Chem. Int. Ed. 2017, 56, 3324-3328. [CrossRef] [PubMed]

28. Shrestha, U.K.; Golliher, A.E.; Newar, T.D.; Holguin, F.O.; Maio, W.A. Asymmetric total synthesis and revision of absolute stereochemistry for (+)-taumycin a: An approach that exploits orthogonally protected quasienantiomers. J. Org. Chem. 2021, 86, 11086-11099. [CrossRef]

29. Mane, S. Racemic drug resolution: A comprehensive guide. Anal. Methods 2016, 8, 7567-7586. [CrossRef]

30. Coulbeck, E.; Eames, J. Parallel kinetic resolution of active esters using a quasi-enantiomeric combination of (R)-4-phenyloxazolidin-2-one and (S)-4,5,5-triphenyl-oxazolidin-2-one. Tetrahedron Asymmetry 2008, 19, 2223-2233. [CrossRef]

31. Petzold, H.; Djomgoue, P.; Hörner, G.; Speck, J.M.; Rüffer, T.; Schaarschmidt, D. ${ }^{1} \mathrm{H}$ NMR spectroscopic elucidation in solution of the kinetics and thermodynamics of spin crossover for an exceptionally robust $\mathrm{Fe}^{2+}$ complex. Dalton Trans. 2016, 45, 13798-13809. [CrossRef]

32. Tinsley, I.C.; Spaniol, J.M.; Wheeler, K.A. Mapping the structural boundaries of quasiracemate fractional crystallization using 2-substituted diarylamides. Chem. Commun. 2017, 53, 4601-4604. [CrossRef] 
33. Woodley, S.M.; Catlow, R. Crystal structure prediction from first principles. Nat. Mater. 2008, 7, 937-946. [CrossRef]

34. Price, S. Predicting crystal structures of organic compounds. Chem. Soc. Rev. 2014, 43, 2098-2111. [CrossRef]

35. Sheldrick, G.M. SADABS and TWINABS_Program for Area Detector Absorption Corrections; University of Göttingen: Göttingen, Germany, 2014.

36. Barbour, L.J. X-Seed 4: Updates to a program for small-molecule supramolecular crystallography. J. Appl. Cryst. 2020, 53, 1141-1146. [CrossRef]

37. Sheldrick, G.M. SHELXT-Integrated space-group and crystal-structure determination. Acta Cryst. A 2015, 71, 3-8. [CrossRef] [PubMed]

38. Sheldrick, G.M. Crystal structure refinement with SHELXL. Acta Cryst. C 2015, 71, 3-8. [CrossRef] [PubMed]

39. Flack, H.D. On enantiomorph-polarity estimation. Acta Cryst. A 1983, 39, 876-881. [CrossRef]

40. Spackman, P.R.; Turner, M.J.; McKinnon, J.J.; Wolff, S.K.; Grimwood, D.J.; Jayatilaka, D.; Spackman, M.A. CrystalExplorer: A program for Hirshfeld surface analysis, visualization and quantitative analysis of molecular crystals. J. Appl. Cryst. 2021, 54, 1006-1011. [CrossRef]

41. Frisch, M.J.; Trucks, G.W.; Schlegel, H.B.; Scuseria, G.E.; Robb, M.A.; Cheeseman, J.R.; Scalmani, G.; Barone, V.; Petersson, G.A.; Nakatsuji, H.; et al. Gaussian 16 Rev. C.01; Gaussian, Inc.: Wallingford, CT, USA, 2016.

42. Groom, C.R.; Bruno, I.J.; Lightfoot, M.P.; Ward, S.C. The cambridge structural database. Acta Cryst. B 2016, 72, 171-179. [CrossRef]

43. Bondi, A. Van der Waals Volumes and Radii. J. Phys. Chem. 1964, 68, 441-451. [CrossRef]

44. Stroustrup, B. The C++ Programming Language, 4th ed.; Addison-Wesley: Upper Saddle River, NJ, USA, 2013; ISBN 978-0-32156384-2.

45. Braun, D.E.; Hald, P.; Kahlenberg, V.; Griesser, U.J. Expanding the solid form landscape of bipyridines. Cryst. Growth Des. 2021, 21, 7201-7217. [CrossRef]

46. Kumar, A.; Singh, P.; Nanda, A. Hot stage microscopy and its applications in pharmaceutical characterization. Appl. Microsc. 2020, 50, 12. [CrossRef] [PubMed]

47. Teng, R.; Wang, L.; Chen, M.; Fang, W.; Gao, Z.; Chai, Y.; Zhao, P.; Bao, Y. Amino acid based pharmaceutical cocrystals and hydrate cocrystals of the chlorothiazide: Structural studies and physicochemical properties. J. Mol. Struct. 2020, 1217, 128432. [CrossRef]

48. Kofler, L.; Kofler, A. Thermal Micromethods for the Study of Organic Ompounds and Their Mixtures; Wagner: Innsbruck, Austria, 1952; McCorne, W.C., Translator; McCorne Research Institute: Chicago, IL, USA, 1980.

49. Kelley, S.P.; Fábián, L.; Brock, C.P. Failures of fractional crystallization: Ordered co-crystals of isomers and near isomers. Acta Crystallogr. Sect. B Struct. Sci. 2011, 67, 79-93. [CrossRef]

50. Rekis, T. Crystallization of chiral molecular compounds: What can be learned from the Cambridge Structural Database? Acta Cryst. B 2020, 76, 307-315. [CrossRef] [PubMed]

51. Hendi, M.S.; Hooter, P.; Davis, R.E.; Lynch, V.M.; Wheeler, K.A. Structural studies of enantiomers, racemates, and quasiracemates: N-(4-methylbenzoyl) methylbenzylamine and N-(4-nitrobenzoyl) methylbenzylamine. Cryst. Growth Des. 2004, 4, 95-101. [CrossRef]

52. Lineberry, A.M.; Benjamin, E.T.; Davis, R.E.; Kassel, W.S.; Wheeler, K.A. Structural studies of racemates and quasiracemates: Chloro, Bromo, and Methyl Adducts of 2-Phenoxypropionic Acid. Cryst. Growth Des. 2008, 8, 612-619. [CrossRef]

53. Cross, J.T.; Rossi, N.A.; Serafin, M.; Wheeler, K.A. Tröger's base quasiracemates and crystal packing tendencies. CrystEngComm 2014, 16, 7251-7258. [CrossRef]

54. Spaniol, J.M.; Wheeler, K.A. Accessing Centnerszwer's quasiracemate-Molecular shape controlled molecular recognition. RSC Adv. 2016, 6, 64921-64929. [CrossRef]

55. Toda, F.; Tanaka, K.; Miyamoto, H.; Koshima, H.; Miyahara, I.; Hirotsu, K. Formation of racemic compound crystals by mixing of two enantiomericcrystals in the solid state. Liquid transport of molecules from crystal to crystal. J. Chem. Soc. Perkin Trans. 1997, 2, 1877-1886. [CrossRef]

56. Fomulu, S.L.; Hendi, M.S.; Davis, R.E.; Wheeler, K.A. Structural studies of enantiomers, racemates, and quasiracemates. N-(2Chlorobenzoyl)methylbenzylamine and N-(2-Bromobenzoyl)methylbenzylamine. Cryst. Growth Des. 2002, 2, 645-651. [CrossRef]

57. Bernstein, J.; Davis, R.E.; Shimoni, L.; Chang, N.-L. Patterns in Hydrogen bonding: Functionality and graph set analysis in crystals. Angew. Chem. Int. Ed. Engl. 1995, 34, 1555-1573. [CrossRef]

58. Etter, M.C.; MacDonald, J.C.; Bernstein, J. Graph-set analysis of hydrogen-bond patterns in organic crystals. Acta Crystallogr. Sect. B Struct. Sci. 1990, 46, 256-262. [CrossRef]

59. Ranjan, S.; Devarapalli, R.; Kundu, S.; Saha, S.; Deolka, S.; Vangala, V.R.; Reddy, C.M. Isomorphism: Molecular similarity to crystal structure similarity in multicomponent forms of analgesic drugs tolfenamic and mefenamic acid. IUCrJ 2020, 7, 173-183. [CrossRef]

60. Spackman, M.A.; Jayatilaka, D. Hirshfeld surface analysis. CrystEngComm 2009, 11, 19-32. [CrossRef]

61. Nicholls, A.; McGaughey, G.B.; Sheridan, R.P.; Good, A.C.; Warren, G.; Mathieu, M.; Muchmore, S.W.; Brown, S.P.; Grant, J.A.; Haigh, J.A.; et al. Molecular shape and medicinal chemistry: A perspective. J. Med. Chem. 2010, 53, 3862-3886. [CrossRef] [PubMed]

62. Bonanno, E.; Ebejer, J.-P. Applying machine learning to ultrafast shape recognition in ligand-based virtual screening. Front Pharm. 2019, 10, 1675. [CrossRef] 
63. Spackman, P.R.; Yu, L.; Morton, C.J.; Parker, M.W.; Bond, C.S.; Spackman, M.A.; Jayatilaka, D.; Thomas, S.P. Bridging Crystal Engineering and drug discovery by utilizing intermolecular interactions and molecular shapes in crystals. Angew. Chem. Int. Ed. 2019, 58, 16780-16784. [CrossRef]

64. Seddon, M.P.; Cosgrove, D.A.; Packer, M.J.; Gillet, V.J. Alignment-free molecular shape comparison using spectral geometry: The framework. J. Chem. Inf. Model. 2019, 59, 98-116. [CrossRef]

65. Ebalunode, J.O.; Ouyang, Z.; Liang, J.; Zheng, W. Novel approach to structure-based pharmacophore search using computational geometry and shape matching techniques. J. Chem. Inf. Model 2008, 48, 889-901. [CrossRef] [PubMed]

66. Rush, T.S.; Grant, J.A.; Mosyak, L.; Nicholls, A. A Shape-Based 3-D Scaffold Hopping Method and Its Application to a Bacterial Protein-Protein Interaction. J. Med. Chem. 2005, 48, 1489-1495. [CrossRef] [PubMed]

67. Wells, R.G.; Sahlstrom, K.D.; Ekelem, F.I.; Wheeler, K.A. Amino acid hydrogen oxalate quasiracemates-Hydrocarbon side chains. CrystEngComm 2021, 23, 8053-8060. [CrossRef]

68. Macrae, C.F.; Sovago, I.; Cottrell, S.J.; Galek, P.T.A.; McCabe, P.; Pidcock, E.; Platings, M.; Shields, G.P.; Stevens, J.S.; Towler, M.; et al. Mercury 4.0: From visualization to analysis, design and prediction. J. Appl. Cryst. 2020, 53, 226-235. [CrossRef]

69. Pérez-Nueno, V.I.; Venkatraman, V.; Mavridis, L.; Clark, T.; Ritchie, D.W. using spherical harmonic surface property representations for ligand-based virtual screening. Mol. Inform. 2011, 30, 151-159. [CrossRef] [PubMed]

70. Cheeseright, T.J.; Mackey, M.D.; Melville, J.L.; Vinter, J.G. FieldScreen: Virtual screening using molecular fields. Application to the dud data Set. J. Chem. Inf. Model. 2008, 48, 2108-2117. [CrossRef] [PubMed]

71. Zhao, Y.H.; Abraham, M.H.; Zissimos, A.M. Fast Calculation of van der Waals Volume as a sum of atomic and bond contributions and its application to drug compounds. J. Org. Chem. 2003, 68, 7368-7373. [CrossRef] [PubMed] 